\title{
The isomorphous structures of prethrombin2, hirugen-, and PPACK-thrombin: Changes accompanying activation and exosite binding to thrombin
}

\author{
J. VIJAYALAKSHMI, ${ }^{1}$ K.P. PADMANABHAN, ${ }^{1}$ K.G. MANN, ${ }^{2}$ AND A. TULINSKY ${ }^{1}$ \\ ${ }^{1}$ Department of Chemistry, Michigan State University, East Lansing, Michigan 48824-1322 \\ ${ }^{2}$ Department of Biochemistry, College of Medicine, University of Vermont, Burlington, Vermont 05405-0068
}

(Received June 29, 1994; ACCEPTED September 6, 1994)

\begin{abstract}
The X-ray crystal structure of prethrombin2 (pre2), the immediate inactive precursor of $\alpha$-thrombin, has been determined at $2.0 \AA$ resolution complexed with hirugen. The structure has been refined to a final $R$-value of 0.169 using 14,211 observed reflections in the resolution range 8.0-2.0 $\AA$. A total of 202 water molecules have also been located in the structure. Comparison with the hirugen-thrombin complex showed that, apart from the flexible beginning and terminal regions of the molecule, there are 4 polypeptide segments in pre 2 differing in conformation from the active enzyme (Pro 186-Asp 194, Gly 216-Gly 223, Gly 142-Pro 152, and the Arg 15-Ile 16 cleavage region). The formation of the Ile 16-Asp 194 ion pair and the specificity pocket are characteristic of serine protease activation with the conformation of the catalytic triad being conserved.

With the determination of isomorphous structures of hirugen-thrombin and D-Phe-Pro-Arg chloromethyl ketone (PPACK)-thrombin, the changes that occur in the active site that affect the kinetics of chromogenic substrate hydrolysis on binding to the fibrinogen recognition exosite have been determined. The backbone of the Ala 190-Gly 197 segment in the active site has an average RMS difference of $0.55 \AA$ between the 2 structures (about $3.7 \sigma$ compared to the bulk structure). This segment has 2 type II $\beta$-bends, the first bend showing the largest shift due to hirugen binding. Another important feature was the 2 different conformations of the side chain of Glu 192. The side chain extends to solvent in hirugen-thrombin, which is compatible with the binding of substrates having an acidic residue in the $\mathrm{P} 3$ position (protein-C, thrombin platelet receptor). In PPACK-thrombin, the side chain of Asp 189 and the segment Arg 221A-Gly 223 move to provide space for the inhibitor, whereas in hirugenthrombin, the Ala 190-Gly 197 movement expands the active site region. Although 8 water molecules are expelled from the active site with PPACK binding, the inhibitor complex is resolvated with 5 other water molecules.
\end{abstract}

Keywords: activation; exosite binding; hirugen-thrombin; PPACK-thrombin; prethrombin2

Prothrombin activation to $\alpha$-thrombin by the prothrombinase complex (Factor Xa-Factor Va-phospholipids- $\mathrm{Ca}^{2+}$ ) initially proceeds through cleavage at Arg 320 (Arg 15, chymotrypsinogen numbering; Fig. 1) to give rise to the intermediate product meizothrombin (Krishnaswamy et al., 1987; Mann, 1987).

Reprint requests to: A. Tulinsky, Department of Chemistry, Michigan State University, East Lansing, Michigan 48824-1322; e-mail: tulinsky@cemvax.cem.msu.edu.

Abbreviations: pre2, prethrombin2; Pre2 (with a capital), hirugenpre2 complex; PPACK, D-Phe-Pro-Arg chloromethyl ketone; Throm, $\alpha$-thrombin; hirugen (Hir), hirudin 53-64; BPTI, bovine pancreatic trypsin inhibitor; DFP, di isopropylfluorophosphate; $\mathrm{PEG}$, polyethyleneglycol; DAPA, dansyl-arginine $N$-(3-ethyl-1,5 pentanediyl)amide.
This is followed by cleavage at Arg 271 to produce $\alpha$-thrombin, which autolytically cleaves at Arg 284 to give $\alpha$-thrombin (des Thr 272-Arg 284) (Downing et al., 1975). The stable form of $\alpha$ thrombin is thus composed of the original residues from prothrombin Thr 285 to Arg 320, which corresponds to the A chain, and Ile 321 to Glu 579 in the B chain. In contrast, the activation of human prothrombin to $\alpha$-thrombin by the catalyst Factor Xa-phospholipid- $\mathrm{Ca}^{2+}$ proceeds by cleavage at Arg 271 that leads to the noncovalently associated products, prothrombin fragment 1.2 (Ala 1-Arg 271) and pre2 (Thr 272-Glu 579). Subsequently, the catalytically inactive pre 2 is cleaved at Arg 320 to $\alpha$-thrombin and, ultimately, to the des Thr 272-Arg 284 cleavage product of $\alpha$-thrombin. Thus, the simplest precursor form 


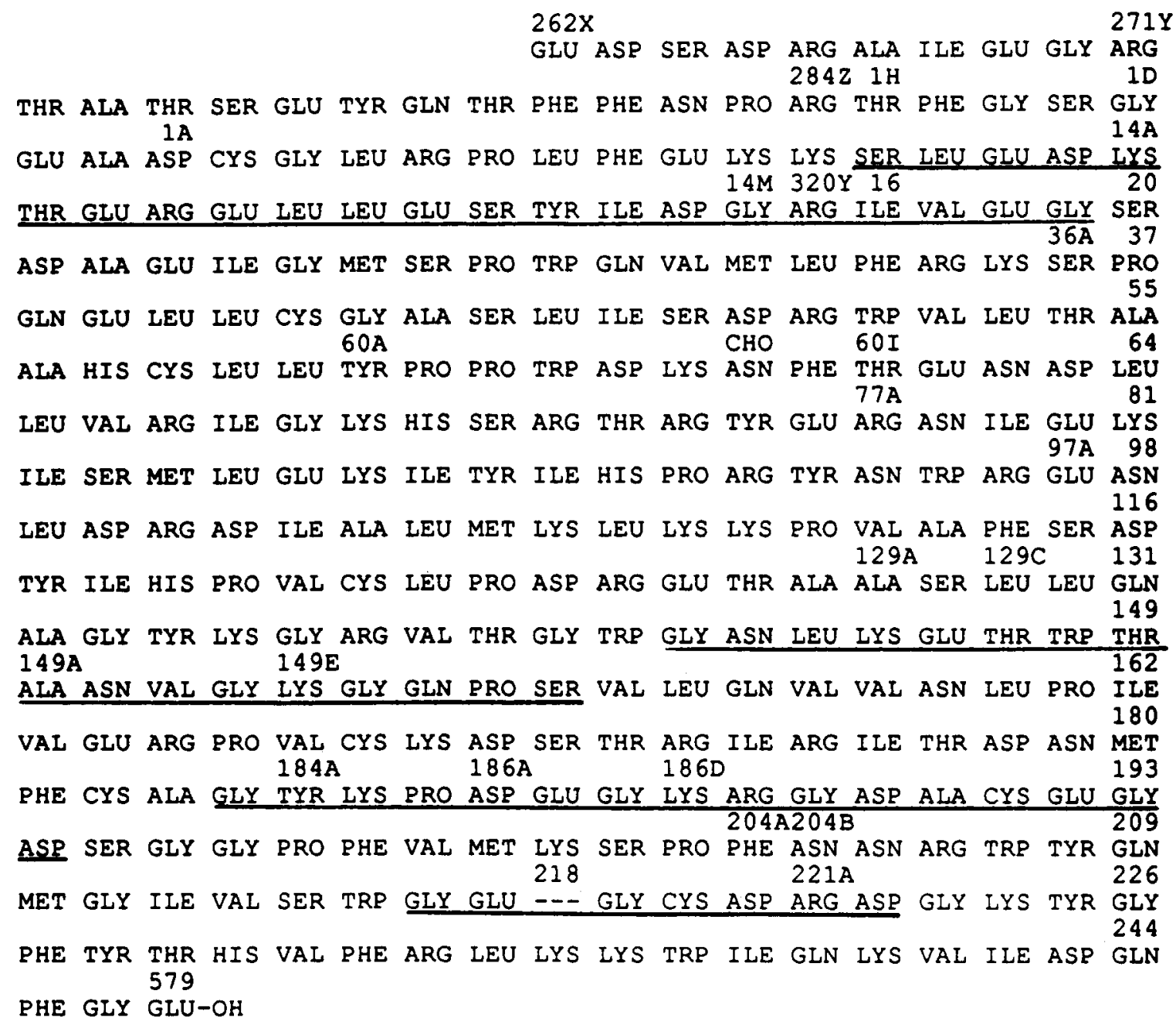

Fig. 1. Amino acid sequence of human pre2. Numbering based on chymotrypsinogen beginning at Thr $1 \mathrm{H}$ (Bode et al., 1992); insertions with respect to chymotrypsinogen denoted with letters; X, N. nigricollis cleavage site (Glu 262); Y, factor Xa cleavage sites (Arg 271, Arg 320); Z, thrombin cleavage site (Arg 284), all in prothrombin numbering; $\mathrm{CHO}, \mathrm{N}$-linked carbohydrate; underlined sequence is the activation domain.

of $\alpha$-thrombin available is pre2. This inactive precursor molecule of $\alpha$-thrombin is most similar to other "simple" serine protease zymogens such as chymotrypsinogen and trypsinogen.

It is difficult to prepare highly purified human pre2 in sufficient quantities for crystallization studies because the enzymes required and formed, Factor $\mathrm{Xa}$ and thrombin, lead to heterogeneous product mixtures (Mann, 1976). For this reason we have made use of a protease recently isolated from the venom of the snake Naja nigricollis nigricollis, which specifically cleaves human prothrombin between Glu 262 and Asp 263 (M.I. Hassan, N.M. Omar, M. Ibrahim, \& K.G. Mann, unpubl. results). The resulting, reasonably stable product is 9 residues longer than pre 2 and can be prepared at high yield and high purity. This material was therefore used as a starting protein for crystallization experiments.

The kinetics of hydrolysis of various chromogenic substrates by thrombin has been found to depend upon binding to the fibrinogen binding exosite (Dennis et al., 1990; Krstenansky et al., 1990; Naski et al., 1990; Hortin \& Trimpe, 1991; Liu et al., 1991a, 1991b). A slight increase in the cleavage rate of a tripeptidyl substrate was reported by Krstenansky et al. (1990) to be due to the binding of a designed synthetic peptide based on the $\mathrm{C}$-terminal of hirudin that contained nonconventional amino acid residues, whereas there is a $60 \%$ decrease in the Michaelis constant for D-phenylalanylpipecolyl arginyl-p-nitroanilide hydrolysis in the presence of hirugen (Dennis et al., 1990). Other studies of amidolytic activity of thrombin (Liu et al., 1991a, 1991b) have suggested active site conformational changes due to binding at the exosite that produce both increased or decreased cleavage rates of small peptidyl substrates of varied sequences.

HPLC gel filtration and CD spectral studies showed conformational changes in thrombin in the presence of hirugen; no $C D$ change, however, was observed with the binding of PPACK (Konno et al., 1988; Mao et al., 1988). A decrease in the ellipticity of the CD spectrum was found upon hirudin-thrombin complex formation compared to the additive sum of the spectra of free thrombin and hirudin, but when thrombin was pre- 
incubated with PPACK, no deviation from additivity occurred. Conversely, the $\gamma$-autolysis loop of PPACK-Throm is about 100 -fold less susceptible to chymotryptic cleavage than the free enzyme, whereas Hir-Throm shows a much smaller effect (only 6-fold less) (Parry et al., 1993).

The structure of $\alpha$-thrombin, the natural and most catalytically active form, has not yet been determined and the likelihood of this accomplishment is not promising because $\alpha$-thrombin readily converts to a less active $\gamma$-form by proteolysis (Fenton et al., 1977; Chang, 1986; Rydel et al., 1994). Although $\gamma$ thrombin is active against small chromogenic substrates and its structure has been determined (Rydel et al., 1994), the fibrinogen recognition exosite is completely disrupted by the autolysis and cannot bind hirugen. Therefore, the determination of the conformational change with hirugen binding by crystallography can at best only be accomplished indirectly. We have succeeded in growing crystals of PPACK-Throm that are isomorphous with Hir-Throm, thus circumventing differences in intermolecular packing interactions that could affect the molecular structures in 2 different crystal forms. Originally, PPACK-Throm was obtained as orthorhombic crystals (Bode et al., 1989; Skrzypczak-Jankun et al., 1989), whereas Hir-Throm crystals are monoclinic (Skrzypczak-Jankun et al., 1991).

We present here the crystal structure determination of Pre2, a new improved structure of Hir-Throm, refined with diffraction measurements that are the average of 2 independent intensity data sets and the refinement of the isomorphous monoclinic structure of PPACK-Throm (also using average data of 2 independent sets) (Kinemage 1). A comparison of the structure of Pre2 with Hir-Throm reveals that the activation domain is like that of trypsinogen and chymotrypsinogen (segments 11-19, 142-153, 184-194, 216-222; Huber \& Bode, 1978) and the conformational changes accompanying catalytic activation are also similar to those of the latter and essentially involve the formation of the S1 specificity site because the catalytic triad of His 57 , Asp 102, Ser 195 (chymotrypsinogen numbering; Fig. 1) is already correctly formed in the inactive precursor. Unlike trypsinogen (Bode \& Huber, 1978; Singh et al., 1980), but like chymotrypsinogen (Freer et al., 1970; Wang et al., 1985), the activation domain is well-defined in Pre2. A comparison of the isomorphous structures of PPACK-Throm and Hir-Throm reveals further the conformational changes that occur at the active center as a result of hirugen binding at the fibrinogen exosite that most likely affect the kinetics of hydrolysis of small chromogenic substrates.

\section{Results and discussion}

\section{General}

There are 308 residues in the Factor Xa cleavage product of pre2. The $N$. nigricollis protease cleavage product contains a 9-residue peptide extension beyond the site of Factor Xa cleavage. The stable, activated $\alpha$-thrombin product is the result of combined Factor $\mathrm{Xa}$ and thrombin cleavage and corresponds to an $\alpha$ thrombin A-chain that begins at Thr $1 \mathrm{H}$ and a B-chain that begins at Ile 16 (Fig. 1). In our studies, the residues corresponding to prothrombin Asp 263-Arg 284 could not be located in the electron density map, implying either flexible disorder or cleavage and removal of the N-terminal peptide. This led to the $\mathrm{N}$-terminal sequencing of the crystal of Pre 2 used for the X-ray intensity data collection. The $\mathrm{N}$-terminal pentapeptide sequence began at Thr $1 \mathrm{H}$ and was Thr Phe Gly Ser Gly. Thus, some thrombin was present in the crystallization solution that liberated the 22-residue $\mathrm{N}$-terminal peptide (Fig. 1). Almost all the remainder of Pre2, however, is well defined in density, including the more flexible regions of the activation domain, hirugen bound in the fibrinogen recognition exosite, and the first $N$ acetylglucosamine of the carbohydrate covalently linked to Asn 60G. The activation domain of trypsinogen is completely disordered, even at low temperatures (Walter et al., 1982), whereas that of chymotrypsinogen is well defined but displays several different conformations among 3 independent molecules of 2 different crystal forms (Freer et al., 1970; Wang et al., 1985).

The Hir-Throm structure refined here with an averaged intensity data set is very similar to the one previously reported (Skrzypczak-Jankun et al., 1991) except for the presence of 2 alternate conformations of Arg 50 and Arg 75 (one of the latter making an intermolecular hydrogen bond with Asp 55 of hirugen) and the appearance of the first sugar of the carbohydrate covalently linked to Asn 60G in the new structure. A superposition of the $2 \mathrm{Hir}$-Throm structures gives an RMS difference of $0.25 \AA$ for $270 \mathrm{C}_{\alpha}$-atoms. Parts of the A-chain of both structures (Thr 1H-Glu 1C, Asp 14L-Arg 15) and the C-terminus of the B-chain did not have good electron density, as well as the loop between Glu 146-Lys 149E, carrying the $\gamma$-cleavage site (Lys 149E-Gly 150). The monoclinic structure of PPACKThrom is very similar to Hir-Throm except Arg 50 and Arg 165 have 2 conformations (the second conformation of Arg 75 is not present in the absence of hirugen). In addition, unlike orthorhombic PPACK-Throm (Bode et al., 1992), the $\gamma$-cleavage loop is completely disordered in monoclinic PPACK-Throm because there are no intermolecular crystal packing interactions. This is not the case in the orthorhombic crystal form (Bode et al., 1992) where the loops of neighboring molecules are localized and stabilized by hydrophobic intermolecular packing interactions (Rydel et al., 1991). In the present structure, the loop is flexibly disordered as in Hir-Throm. Otherwise, the molecular structure of monoclinic PPACK-Throm is practically the same as the orthorhombic structure (RMS $\Delta=0.29 \AA$ for $270 C_{c x}$-atoms) and, except for active site changes, similar to that of Hir-Throm ( 0.25 for $270 \mathrm{C}_{\alpha}$-atoms). These comparisons and those throughout the remainder of the communication that involve HirThrom or PPACK-Throm will be with respect to the new averaged data set structures unless designated differently.

Most of the polypeptide segments of Pre2 differing in conformation from thrombin were found to possess relatively high temperature factors. These regions include: Thr $1 \mathrm{H}-\mathrm{Glu} 1 \mathrm{C}$; Glu 14H-Glu 18; Glu 146-Gln 151 ( $\gamma$-loop); Pro 186-Arg 187; Gly 219-Gly 223, and the C-terminal residues Asp 243-Glu 247. This indicates that some of the regions of the precursor protein become stabilized upon activation because their thermal parameters are normal in the structures of PPACK- and Hir-Throm. Some, however, become less well defined or completely disordered in the active enzyme (Thr 1H-Glu 1C; Asp 14L-Arg 15 [newly formed C-terminal of A-chain]; Glu 146-Lys 149E of the autolysis loop). The $\mathrm{C}_{\alpha}$ structures of Pre2 and Hir-Throm are compared in Figure 2 and Kinemage 1, whereas ribbon drawings (Priestle, 1988) of the secondary structural features of the two are shown in Figure 3. A superposition of Pre2 (less the activation domain) and Hir-Throm gives an RMS difference of 


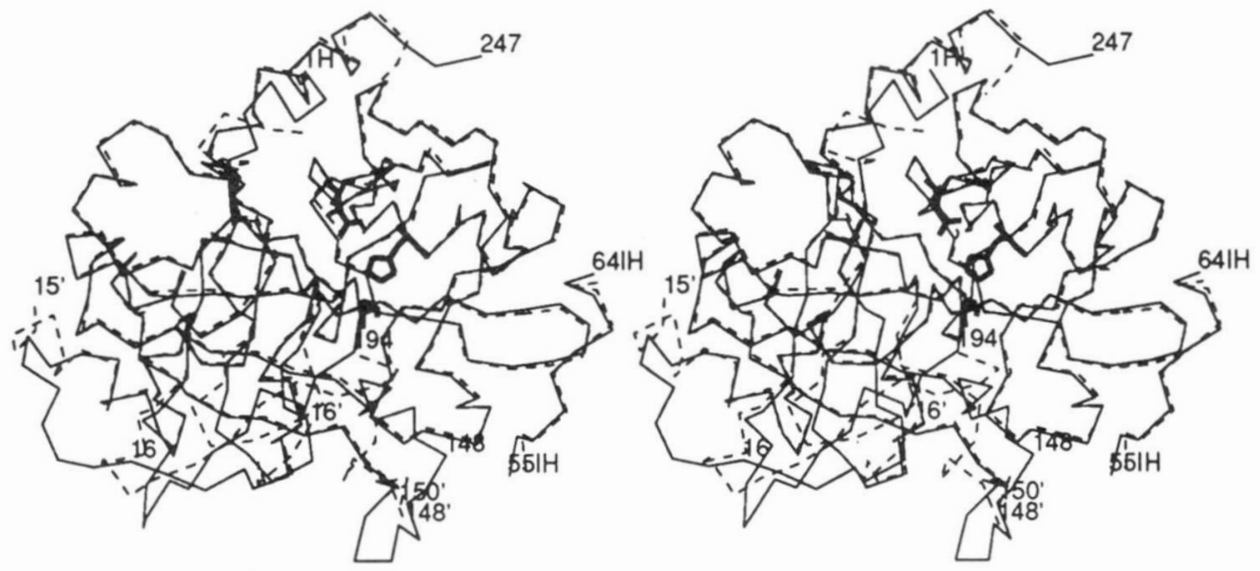

Fig. 2. Stereo view of $\mathrm{C}_{\alpha}$ superposition of Pre2 and Hir-Throm. Solid lines, Pre2; broken lines, Hir-Throm; hirugen denoted $55 \mathrm{IH}-64 \mathrm{IH}$; side chains of catalytic triad (His 57, Asp 102, Ser 195) in bold; primed numbers, Hir-Throm; $148^{\prime}$ and $150^{\prime}$ are $\mathrm{C}$ - and $\mathrm{N}$-terminals of disordered $\gamma$-autolysis loop of Hir-Throm.

$0.25 \AA$ for $214 \mathrm{C}_{\mathrm{a}}$-atoms. The largest number of differences occur in the C-terminal barrel, which contains 3 segments of the activation domain and the S1 specificity site, and in the separation of Arg 15 and Ile 16 in thrombin (Fig. 3). The N- and C-terminal regions of Pre2 and Hir-Throm are also different.

\section{Activation domain}

The $2\left|F_{o}\right|-\left|F_{c}\right|$ electron density of the Arg 15-Ile 16 cleavage region of the activation domain of Pre2, which is fairly typical of the latter, is shown in Figure 4A; the structure of the region is compared with that of Hir-Throm in Figure 4B. The conformation of Pre2 begins to differ from thrombin at Glu $14 \mathrm{H}$, where it has an additional helical turn in thrombin (Figs. 3, 4;
Kinemage 1). In Pre2, this segment is in a more extended loop conformation and linked to Ile 16 . The newly formed Ile 16 $\mathrm{N}$-terminal of thrombin is buried in the active center, where it makes a hydrogen bonded ion pair with Asp 194 ( $2.5 \AA$ ). The deviations between Pre 2 and thrombin increase steadily up to the amide of Ile 16, which in Pre2 is about $15 \AA$ from the carboxylate group of Asp 194. The conformations of the 2 molecules become similar again around Ser 20. This Factor Xa cleavage site region of Pre 2 displays the largest deviations in structure between Pre2 and thrombin (Table 1).

Equally important but somewhat smaller changes accompany activation between Ala 183-Pro 198 and Val 213-Phe 227 of the activation domain (Figs. 5, 6; Table 1). The peptide between Cys 191 and Cys 220 is involved in forming the S1 specificity and
A

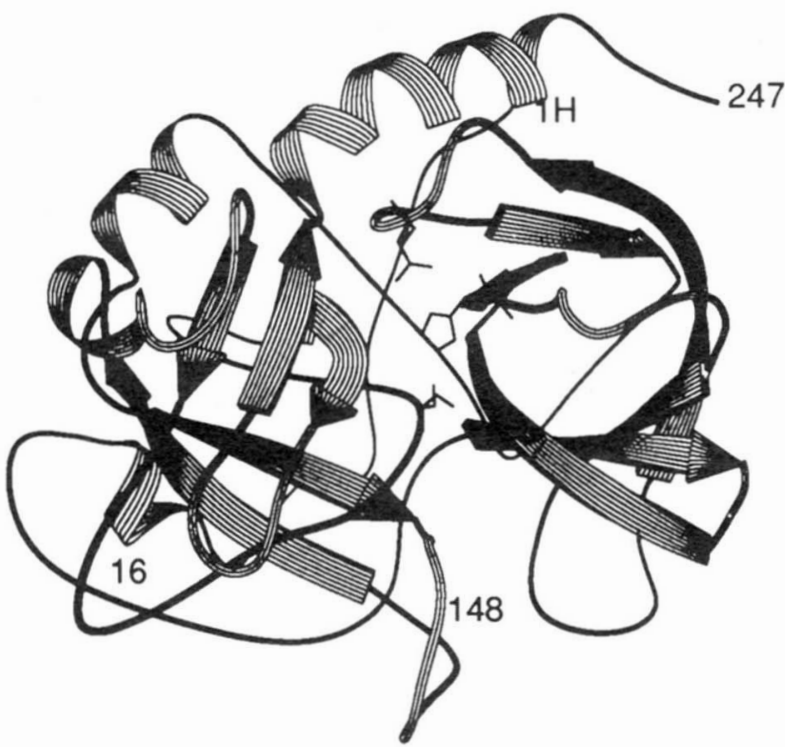

B

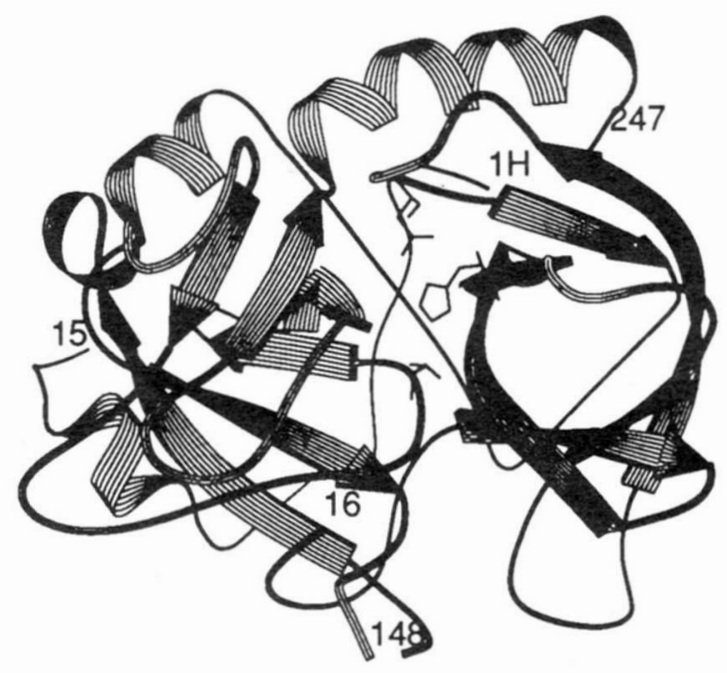

Fig. 3. Ribbon representation of the secondary structures of Pre2 (left) and Hir-Throm (right). N- and C-terminals of thrombin numbered $(1 \mathrm{H}, 247)$ in addition to Arg 15-Ile 16 cleavage site and position Trp 148 of disordered autolysis loop of HirThrom; catalytic triad, thin lines; only a small number of minor changes in the N-terminal antiparallel $\beta$-sheet barrel (16-115, to the right) but many more in C-terminal barrel (140-235, to the left). 

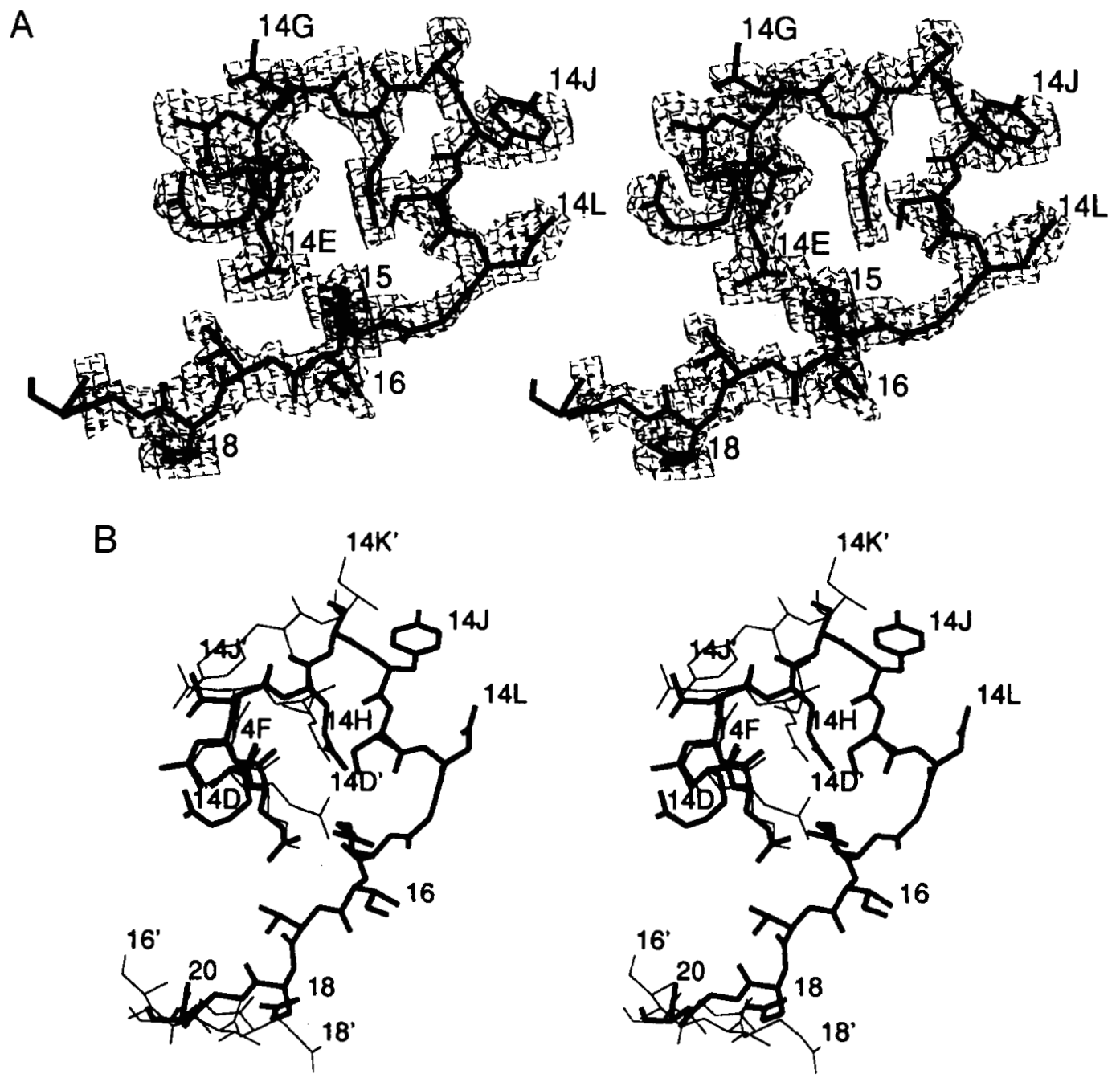

Fig. 4. Final $2\left|F_{o}\right|-\left|F_{c}\right|$ electron density map of the cleavage site Arg 14D-Gly 19 segment of the activation domain of Pre2

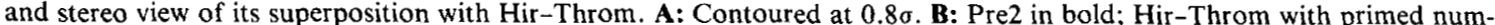
bers; Arg 15' and Ile 16' are $\mathbf{C}$ - and $\mathrm{N}$-terminii in activated molecule.

S2 binding subsites (Schechter \& Berger, 1967) of the active site region and contains Ser 195 of the catalytic triad. In Pre2, it has

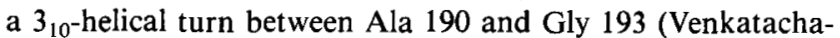
lam, 1968; Crawford et al., 1973) with Glu 192 buried in a position close to Ile 16 of thrombin. The turn leads to a hydrogen bond: Ala 1900-Gly 193 N (3.2 Å). Thrombin has a type II $\beta$ bend conformation here but between Cys 191 and Asp 194 (Cys 1910-Asp 194N, 3.0 ̊), and both Pre2 and thrombin have a type II turn between Asp 194 and Gly 197 (Asp 194O-Gly $197 \mathrm{~N}, 2.8$ and $3.0 \AA$, respectively). The movement of the first turn results in a different conformation for the Cys 191-Cys 220 region (Fig. 5; Table 1). The most critical event in the activation of zymogen to active enzyme following the cleavage of the Arg 15-Ile 16 bond in Pre2 appears to be the formation of the ion pair between the $\mathrm{N}$-terminal Ile 16 and the carboxylate of Asp 194 (Kinemage 1), similar to trypsinogen and chymotrypsinogen activation (Freer et al., 1970), which is also accompanied by solvent exposure of buried Glu 192. The unfolding of the turn between Ala 190 and Gly 193 and its subsequent dis- placed reformation at Cys 191-Asp 194 simultaneously forms most of the S1 specificity subsite.

The hydrogen bonded antiparallel $\beta$-strand interactions observed in Pre 2 between Ser 214 and Phe 227 are not present in Hir-Throm (Table 2; Fig. 6). Moreover, Pre2 has a turn between Gly 219 and $\operatorname{Arg} 221 \mathrm{~A}$, which does not occur in thrombin. The Ser 214-Glu 217 stretch in the active site region is a crucial determinant of peptide substrate interactions with thrombin, with which P1-P3 subsites of substrates generally form an antiparallel $\beta$-strand. A striking exception is Ile 1-Tyr 3 of hirudin, which makes a parallel $\beta$-strand with Ser 214-Glu 217 (Rydel et al., 1991). The reorientation of Arg 221 A (Fig. 6) appears to be equally crucial for an ion pair interaction with acidic residues at P3 that occurs with thrombin platelet receptor (Ni et al., 1992; Mathews et al., 1994) and most likely protein C.

The catalytic triad of thrombin, including its hydrogen bonding network (Skrzypczak-Jankun et al., 1991), is already prearranged in Pre2 but the oxyanion hole near Gly 193 (Henderson, 1970; Robertus et al., 1972) is not present. The RMS difference in the 
Table 1. Large well-defined RMS differences between the structures of Pre2 and Hir-Throm ${ }^{\mathrm{a}}$

\begin{tabular}{lcccc}
\hline \hline Segment & $\begin{array}{c}\text { All atoms } \\
(\AA)\end{array}$ & $\begin{array}{c}\text { Main } \\
(\dot{\mathrm{A}})\end{array}$ & $\begin{array}{c}\text { Side } \\
(\AA)\end{array}$ & $\begin{array}{c}\text { Sulfur } \\
(\AA)\end{array}$ \\
\hline Arg 14D-Arg 15 & $9.9(94)$ & $8.5(33)$ & $10.7(50)$ & - \\
Ile 16-Asp 21 & $8.6(42)$ & $8.2(18)$ & $9.7(18)$ & - \\
Trp 141-Gln 146 & $6.6(52)$ & $5.1(18)$ & $7.6(28)$ & - \\
Gly 150-Val 154 & $1.8(33)$ & $1.5(15)$ & $2.1(13)$ & - \\
Ala 183-Gly 188 & $5.2(82)$ & $2.7(33)$ & $7.0(38)$ & - \\
Asp 189-Pro 198 & $4.7(61)$ & $3.4(30)$ & $6.6(21)$ & $4.3(1)$ \\
Val 213-Phe 227 & $3.7(117)$ & $2.3(45)$ & $4.6(57)$ & $2.3(1)$ \\
Gln 239-Glu 247 & $5.2(75)$ & $3.7(27)$ & $6.2(39)$ & -
\end{tabular}

${ }^{a}$ Number of atoms in comparison in parentheses.

positions of His 57, Asp 102, and Ser 195 between zymogen and enzyme is about $0.37 \AA$ including side-chain atoms. Superposition of the $\mathrm{C}_{\alpha}$-structure common to both ( 214 residues) gives the same RMS deviation for the catalytic triad, which indicates that the triad is not shifted with respect to the conserved structure during activation (Kinemage 1), in agreement with similar observations with chymotrypsinogen (Wang et al., 1985). Thus, as with other serine proteinases, the most important aspect of activation of Pre 2 to thrombin appears to be the conversion of a partially formed specificity pocket in the zymogen to a fully formed S1 site in the enzyme.

Like single chain tissue-type plasminogen activator, Pre 2 does not possess a "zymogen triad" of Ser 32, His 40, Asp 194 of the chymotrypsin family but, unlike the activator, it does not show catalytic activity. Introducing a Ser 32 and His 40 in the plasminogen activator reduces catalytic activity by a factor of about 150 (Madison et al., 1993). These residues are Met 32 and Leu 40 in Pre2 and along with Trp 141 form a hydrophobic cavity around Asp 194. The charge of Asp 194 appears to be compensated only by the nearby polar presence of Gln 30 and Asn 143 . Therefore, the lack of the zymogen triad is not sufficient to produce catalytic activity in Pre2.
In contrast to most other serine proteases, there is a nonuniform distribution of charges in thrombin where an electronegative active center is between 2 discrete highly electropositive surface regions (Rydel et al., 1990; Bode et al., 1992; Karshikov et al., 1992). One of these cationic exosites is the fibrinogen recognition site (Fenton, 1981, 1986), whereas the other is most likely the heparin binding site (Church et al., 1989; Karshikov et al., 1992; Arni et al., 1993). The fibrinogen exosite lies between surface loops Leu 33-Leu 41 and Arg 67-Lys 81 with Lys 109-Lys 110 nearby. The positive charge is due mainly to $\operatorname{Arg} 73$, Arg 75, and Arg 77A because the other positive residues are involved in salt bridges (Bode et al., 1992). The active site has a net negative charge resulting from Glu 97A, Asp 102, Glu 146, Asp 189, Glu 192, and Glu 217.

The fibrinogen recognition exosite has been shown to be present in pre2, the prothrombin fragment 2-pre2 complex, and meizothrombin (Liu et al., 1991b). Therefore, not surprisingly, NMR measurements also show partial accessibility to the site in prothrombin (Ni et al., 1993). However, studies with thrombomodulin and autoantibody D demonstrate that the exosite is not accessible in human recombinant pre2 (Wu et al., 1994). In Pre2, the fibrinogen binding site is also preformed, like the catalytic triad, and has practically the same structure as that in HirThrom. Moreover, hirugen binds noncovalently to Pre2 in an identical manner. Thus, it may be possible that the small size and greater flexibility enable hirugen to bind to regions on Pre2 that are not accessible to macromolecules such as thrombomodulin. The RMS difference in main-chain positions of hirugen is only $0.53 \AA$; the RMS deviation of the side groups, which are solvent accessible, is somewhat larger at $1.0 \AA$. Superposition of 214 common residues again gives the same deviations, indicating that the hirugen is not shifted in the precursor structure. The limited accessibility of the site in prothrombin may be the result of partial obstruction by the inter-kringle-catalytic domain peptide, which is missing in the crystal structure of Pre2.

Although the $\gamma$-autolysis loop region of thrombin was included in the activation domain of trypsinogen and other serine proteinases by Bode and Huber (1978), in many respects (flexibility, susceptibility to cleavage, solvent exposure) it tends to behave like an autonomous-like structure. In the absence of
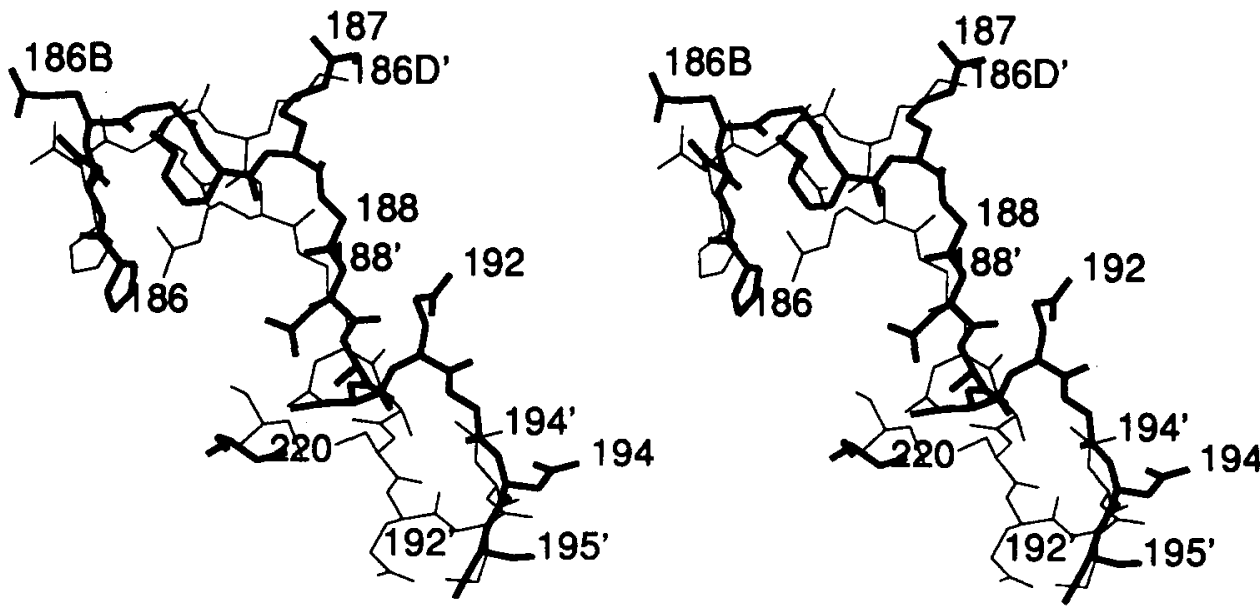

Fig. 5. Stereo view of superposition of Pro 186-Ser 195 of Pre2 and Hir-Throm. Pre2 in bold; primed numbers correspond to Hir-Throm. 

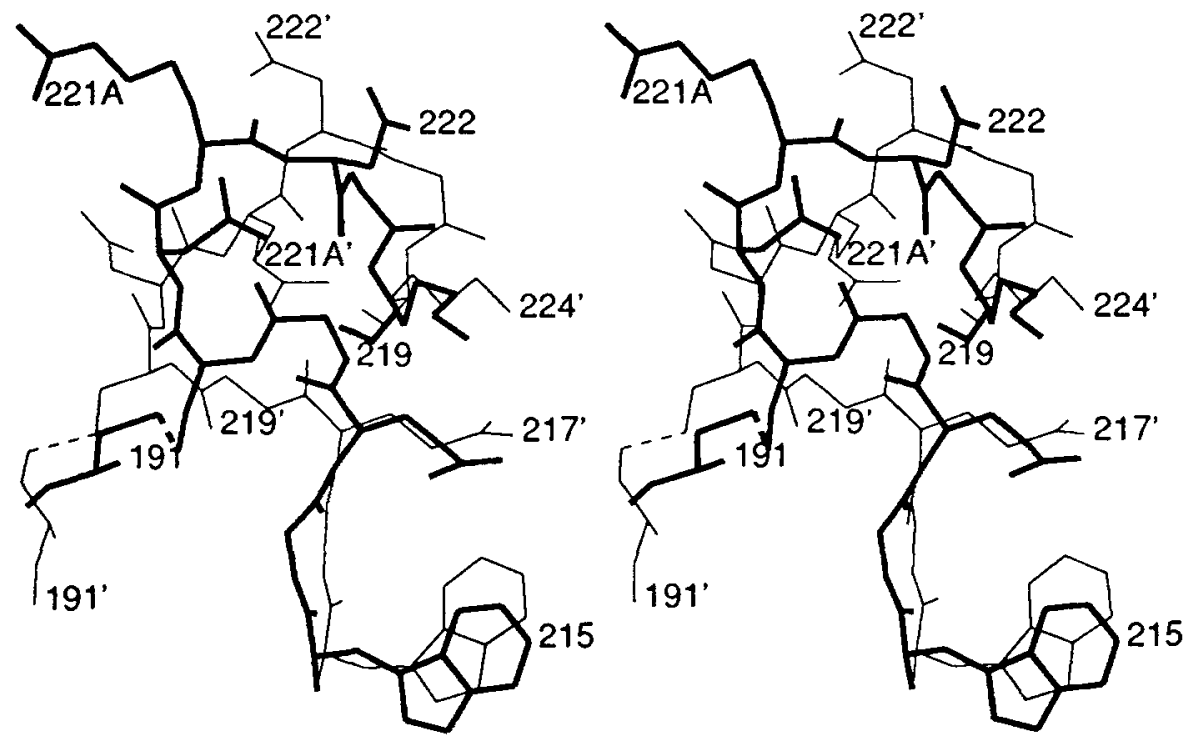

Fig. 6. Stereo view of superposition of Trp 215-Lys 224 of Pre2 and Hir-Throm. Pre2 in bold; disulfide bond broken; primed numbers correspond to Hir-Throm.

intermolecular crystal contacts, the autolysis loop (Glu 146Lys $149 \mathrm{E}$ ) of thrombin is generally disordered. This includes monoclinic crystals grown at neutral $\mathrm{pH}$ such as Hir-Throm (Skrzypczak-Jankun et al., 1991) and related derivatives and isomorphous PPACK-Throm. Orthorhombic crystals of HirThrom-related derivatives (space group $\mathrm{P} 2{ }_{1} 2{ }_{1} 2$ ) grow at acid pH values ( 4.0) (Chirgadze et al., 1992; Priestle et al., 1993), where the $\gamma$-loop of thrombin has a well-defined conformation but interacts with symmetry-related neighboring molecules. The same occurs in crystals of hirudin-thrombin and orthorhombic PPACK-Throm (Rydel et al., 1991). The only conformationally defined autolysis loop of thrombin that is independent of intermolecular contacts is found in a thrombin platelet receptor peptide-thrombin complex (Mathews et al., 1994). Another is in the structure of Pre2 (Fig. 7A) where nearly all the residues (except Thr $147 \mathrm{~N}$, Trp 148CA and CB, and the side group of Thr 149) are located in electron density. Because the loop is part of the activation domain, however, its relevance to the structure of thrombin remains to be shown. The fact that it is ordered in Pre2 suggests that the loop is most likely ordered in prothrombin.

Due to the proximity of Asp 189-Asp 194 to the $\gamma$-cleavage loop and hydrogen bonding interactions between Trp 141Lys 145 and Gly 193-Ser 195 (Table 2), the shift in the Pre2 Ala $190-$ Gly 193 turn to a type II $\beta$-bend conformation most likely causes the turn at Gly 142-Lys 145 (borderline between $3_{10}$ and type I with Gly $142 \mathrm{O}-\mathrm{Lys} 145 \mathrm{~N}, 3.1 \AA$ ) to become more extended in thrombin (Figs. 2, 7B). The absence of a side group and the relative mobility of a glycine (Gly 142 ) probably aids in the movement of the stretch during activation that results in a large difference between the 2 structures (RMS $\Delta=6.6 \AA$; Table 1): in Pre2, Leu 144 is in the vicinity of active site Glu 192 of Hir-Throm. Furthermore, the guanidinium group of Arg 145 appears to play a role of stabilizing the internal negative charges of Asp 102 and Asp 194 at the surface of chymotrypsinogen, which can form hydrogen bonds through water molecules to both His 40ND1 and Ser 195OG (Wright, 1973). This does not occur in Pre 2 because Gly 142-Asn 143 of the $\beta$-bend is between
Lys 145 and the negative groups. The different structure is essentially the result of the different conformation of the 142152 region in the 2 zymogens; in chymotrypsinogen, Trp 141 Tyr 146 is in an $\alpha$-helix.

The exposed $\gamma$-cleavage loop of thrombin in a platelet receptor peptide-thrombin complex has some side groups that are not defined in electron density but the path of the peptide chain is clear and definite (Mathews et al., 1994). The conformation, however, is very different from that of Pre2. In the latter, it assumes a more open loop structure, whereas in the former it is much more compact and even has a small antiparallel $\beta$-strand component (Mathews et al., 1994). The RMS difference in the main-chain positions between the two is over $6.0 \AA$. Whether the conformation of the loop in the receptor peptide-thrombin complex is, however, the only stable native conformation for the active enzyme must still be established.

The $\mathrm{C}_{\alpha} \mathrm{CN}$ conformation of Arg 15-Ile 16 of the Factor Xa activation cleavage region of Pre2 (Fig. 4B; Table 3) was compared to the putative scissile bond region of BPTI in the BPTItrypsin complex (Huber et al., 1974) and the comparison was extended to the $\beta$-cleavage site of $\alpha$-thrombin and the scissile bond of chymotrypsinogen. Tri- and tetrapeptide conformations around the $\beta$-cleavage site have structures similar to the bound conformation of BPTI in the active site of trypsin. In addition, the conformations are close to those of thrombin-bound hiru$\log 3$ (Qiu et al., 1992) and hirutonin (Zdanov et al., 1993). The binding of these $2 \mathrm{P} 1$ subsite-altered inhibitors with a nonhydrolyzable bond at the scissile position by thrombin is a close approximation of a fibrinogen exosite-occupied enzymesubstrate complex prior to catalysis. Thus, the thrombin $\beta$-site, which is prone to attack, has a conformation favored for proteolysis. Another cleavage site may exist near the $\beta$-site between Arg 75 and Tyr 76 (Rydel et al., 1994). The conformation of this stretch is also similar to that of bound BPTI (Table 3 ).

The optimal conformation of the reactive site loops of protease protein inhibitors for binding to serine proteinases is well documented crystallographically. This canonical structure, how- 
Table 2. Comparison of the hydrogen bonds and salt bridges of the activation domain of Pre2 and Hir-Throm

\begin{tabular}{|c|c|c|c|c|c|c|c|}
\hline \multirow[b]{2}{*}{ Donor } & \multicolumn{4}{|c|}{ Pre2 } & \multicolumn{3}{|c|}{ Hir-Throm } \\
\hline & Acceptor & Donor & Acceptor & $d(\dot{A})$ & Donor & Acceptor & $\mathrm{d}(\AA)$ \\
\hline Arg 14D & $\mathrm{NH} 1$ & Glu 13 & OEI & $3.0^{\mathrm{b}}$ & & & \\
\hline Arg 14D & $\mathrm{NH} 2$ & Tyr 14J & $\mathrm{OH}^{\mathrm{a}}$ & 2.9 & & & \\
\hline Glu 14E & $\mathrm{O}$ & Glu $14 \mathrm{H}$ & N & 3.2 & & & \\
\hline \multirow[t]{3}{*}{ Glu 14E } & $\mathrm{N}$ & & & & Thr 14B & $\mathrm{O}$ & 3.1 \\
\hline & $\mathrm{OE} 1$ & Lys 135 & $\mathrm{NZ}$ & $2.7^{\mathrm{b}}$ & Lys 135 & $\mathrm{NZ}$ & $3.0^{6}$ \\
\hline & OE2 & Asn 159 & ND2 & 2.8 & Asn 159 & ND2 & 3.0 \\
\hline Leu $14 \mathrm{~F}$ & $\mathrm{O}$ & & & & Ser 14I & OG & 2.7 \\
\hline Leu $14 \mathrm{G}$ & $\mathrm{O}$ & & & & Tyr 14J & $\mathrm{N}$ & 3.1 \\
\hline \multirow[t]{2}{*}{ Glu $14 \mathrm{H}$} & $\mathrm{O}$ & & & & Asp 14L & $\mathrm{N}$ & 3.2 \\
\hline & OE2 & Arg 15 & $\mathrm{NH} 2^{\mathrm{a}}$ & $2.8^{\mathrm{b}}$ & Arg 14D & $\mathrm{NHI}$ & $2.9^{\mathrm{b}}$ \\
\hline Arg 15 & $\mathrm{O}$ & Lys 135 & $\mathrm{NZ}$ & 2.6 & & & \\
\hline $\operatorname{Arg} 15$ & $\mathrm{NH} 2$ & & & & Phe 204A & $\mathrm{OH}$ & 2.9 \\
\hline $\operatorname{Arg} 15$ & OXT & & & & Arg 173 & $\mathrm{O}^{\mathrm{a}}$ & 2.8 \\
\hline Ile 16 & $\mathrm{~N}$ & & & & Asp 194 & OD1 & $2.5^{b}$ \\
\hline Glu 18 & OE2 & Arg 187 & $\mathrm{NH}_{2}$ & $2.8^{\mathrm{b}}$ & & & \\
\hline Gly 19 & $\mathrm{O}$ & Gln 156 & NE2 & 3.0 & & & \\
\hline Gly 142 & 0 & Lys 145 & $N$ & 3.1 & & & \\
\hline Leu 144 & $\mathrm{~N}$ & & & & Gly 150 & $\mathrm{O}$ & 2.8 \\
\hline Asn 149B & OD1 & Gln 244 & $N E 2^{a}$ & 2.8 & & & \\
\hline Lys 185 & $\mathrm{~N}$ & & & & Glu 186B & OE2 & 2.6 \\
\hline Arg 187 & NH1 & & & & Asp 222 & OD2 & $3.2^{b}$ \\
\hline Arg 187 & $\mathrm{NH} 2$ & & & & Asp 222 & OD1 & $3.2^{\mathrm{b}}$ \\
\hline \multirow[t]{2}{*}{ Asp 189} & $\mathrm{O}$ & & & & Val 17 & $\mathrm{~N}$ & 2.8 \\
\hline & $N$ & & & & Val 17 & $\mathrm{O}$ & 3.0 \\
\hline Ala 190 & $\mathrm{O}$ & Gly 193 & $\mathbf{N}$ & 3.2 & & & \\
\hline \multirow[t]{2}{*}{ Cys 191} & $\mathrm{~N}$ & & & & Asp 194 & OD1 & 2.9 \\
\hline & $\mathrm{O}$ & & & & Asp 194 & $\mathrm{~N}$ & 3.0 \\
\hline Glu 192 & $\mathrm{O}$ & & & & Asn 143 & $\mathrm{~N}$ & 2.8 \\
\hline \multirow[t]{3}{*}{ Asp 194} & $\mathrm{O}$ & Gly 197 & $\mathrm{~N}$ & 2.8 & Gly 197 & $\mathrm{~N}$ & 3.0 \\
\hline & OD1 & Asn 143 & $\mathrm{~N}$ & 3.0 & & & \\
\hline & OD2 & Trp 141 & $\mathrm{~N}$ & 3.0 & Gly 142 & $\mathrm{~N}$ & 2.8 \\
\hline Ser 195 & $N$ & Asn 143 & OD1 & 3.1 & & & \\
\hline Ile 212 & $\mathrm{O}$ & Thr 229 & $\mathrm{~N}$ & 3.0 & & & \\
\hline Ser 214 & $\mathrm{~N}$ & Phe 227 & $\mathrm{O}$ & 2.7 & & & \\
\hline Trp 215 & $\mathrm{O}$ & Phe 227 & $\mathrm{~N}$ & 2.8 & & & \\
\hline Glu 217 & OEl & Thr 172 & OG1 & 3.0 & & & \\
\hline \multirow[t]{2}{*}{ Glu 217} & OE2 & & & & Lys 224 & NZ & $3.2^{\mathrm{b}}$ \\
\hline & $\mathrm{N}$ & Tyr 225 & $\mathrm{O}$ & 2.6 & & & \\
\hline
\end{tabular}

${ }^{a}$ Intermolecular hydrogen bond.

${ }^{b}$ Hydrogen bonded ion pair.

ever, does not occur among many limited proteolytic sites or nicksites, which have very different conformations that are also different from the consensus conformation of the protein inhibitors (Hubbard et al., 1991, 1994). Modeling results suggest that motions close to the scissile bond are required for proteolysis. The $\mathrm{C}_{\alpha} \mathrm{CN}$ conformations of the Factor $\mathrm{Xa}-\mathrm{Pre} 2$ cleavage site (Arg 15-lle 16) (Fig. 4B) and that of chymotrypsinogen and the $\beta$-site of thrombin are the same, but only after a $180^{\circ}$ rotation of the Pre2 site with respect to the bulk of the protein (Table 3 ). The $\beta$-site has been shown to be readily dockable in the active site of thrombin (Rydel et al., 1994). Because the active sites of thrombin and Factor Xa are similar (Padmanabhan et al., 1993), the Pre 2 site can be docked in the active site of Factor Xa similarly, but only after a reorientation of the peptide involving the region of the scissile bond. The sequence around the scissile bond is Gly Arg Ile Val Glu Gly. Docking, however, can be achieved with a conformational change of about $150^{\circ}$ around the glycine hinge points. Activation of Pre2, and most likely prothrombin, by Factor Xa may proceed accompanied by such a change. This inference is especially intriguing in view of the significant increase in the $k_{c a t}$ for prothrombin activation that is realized when Factor Xa acts as a component of the prothrombinase complex. At physiologic protein concentrations the prothrombinase complex is 5 orders of magnitude more active than free Factor $\mathrm{Xa}$ acting on prothrombin. Although part of this increase in efficiency can be explained by the membraneinfluenced concentration of Factor $\mathrm{Xa}$ and prothrombin, the most significant contribution is in the $k_{c a t}$ associated with Factor $\mathrm{Xa}$-prothrombin peptide bond cleavage. The induction of significant alterations in the conformation of the substrate cleavage site, the enzyme active site, or both, in the complex may explain this aspect of prothrombinase efficiency.

The Arg 15-Ile 16 activation cleavage within Pre2 that produces thrombin is accompanied by an intrinsic fluorescence change of about $35 \%$ (Stevens \& Nesheim, 1993). Examination of the structures of Pre 2 and Hir-Throm reveals that these changes are most likely due to $\operatorname{Trp} 141, \operatorname{Trp} 148, \operatorname{Trp} 215$, and possibly Trp 51. The side chain of Trp 215 of the Ser 214Glu 217 stretch that generally forms an antiparallel $\beta$-strand with peptide substrates undergoes a change in orientation $\left(\Delta \chi_{1}=\right.$ $49^{\circ}, \Delta \chi_{2}=16^{\circ}$ ) and Trp 141 does likewise but to a lesser degree. Both of the residues are at the beginning of different segments of the activation domain so some movement is inevitable. An even larger contribution to the fluorescence change may be the result of structural changes in the immediate environment of these indoles and that of Trp 51; the latter, however, is positionally the same in both structures. Because Trp 148 is in an activation segment, which is also very mobile, it must contribute substantially to the fluorescence event. None of the remaining indoles nor their environment are different.

Stevens and Nesheim (1993) also studied the modification of the tryptophans in Pre2 and thrombin by oxidation with $N$ bromosuccinimide. They concluded that Trp 29 and Trp 51 were more accessible in Pre2, whereas the accessibility of Trp 60D and $\operatorname{Trp} 207$ or Trp 215 or both is somewhat diminished. However, the tryptophan residues of $51,60 \mathrm{D}, 96,141,148,215$, and 237 are all readily accessible in both structures, whereas those of 29 and 207 are buried. Therefore, the apparent accessibilities of Trp 29 and Trp 60D to oxidation in Pre2 are probably related to factors other than steric hindrance. The hindered accessibility of Trp 215 in Pre2 is most likely the result of the ordered structure of the nearby $\gamma$-autolysis loop, although the region is relatively open in both zymogen and enzyme.

Most of the activation domain of Pre2 has high temperature factors $\left(42-50 \AA^{2}\right)$. In trypsinogen, the domain is completely disordered (Bode \& Huber, 1978), even at low temperatures (Singh et al., 1980; Walter et al,, 1982), whereas it shows several distinct conformations in independent molecules of chymotrypsinogen (Freer et al., 1970; Wang et al., 1985). Contrary to general expectations accompanying large $B$-values, the electron density of the activation domain of Pre2, representative in Figures $4 \mathrm{~A}$ and $7 \mathrm{~A}$, is well defined. Because the average $B$-value of the domain is about $17 \AA^{2}$ larger than that of the remainder 

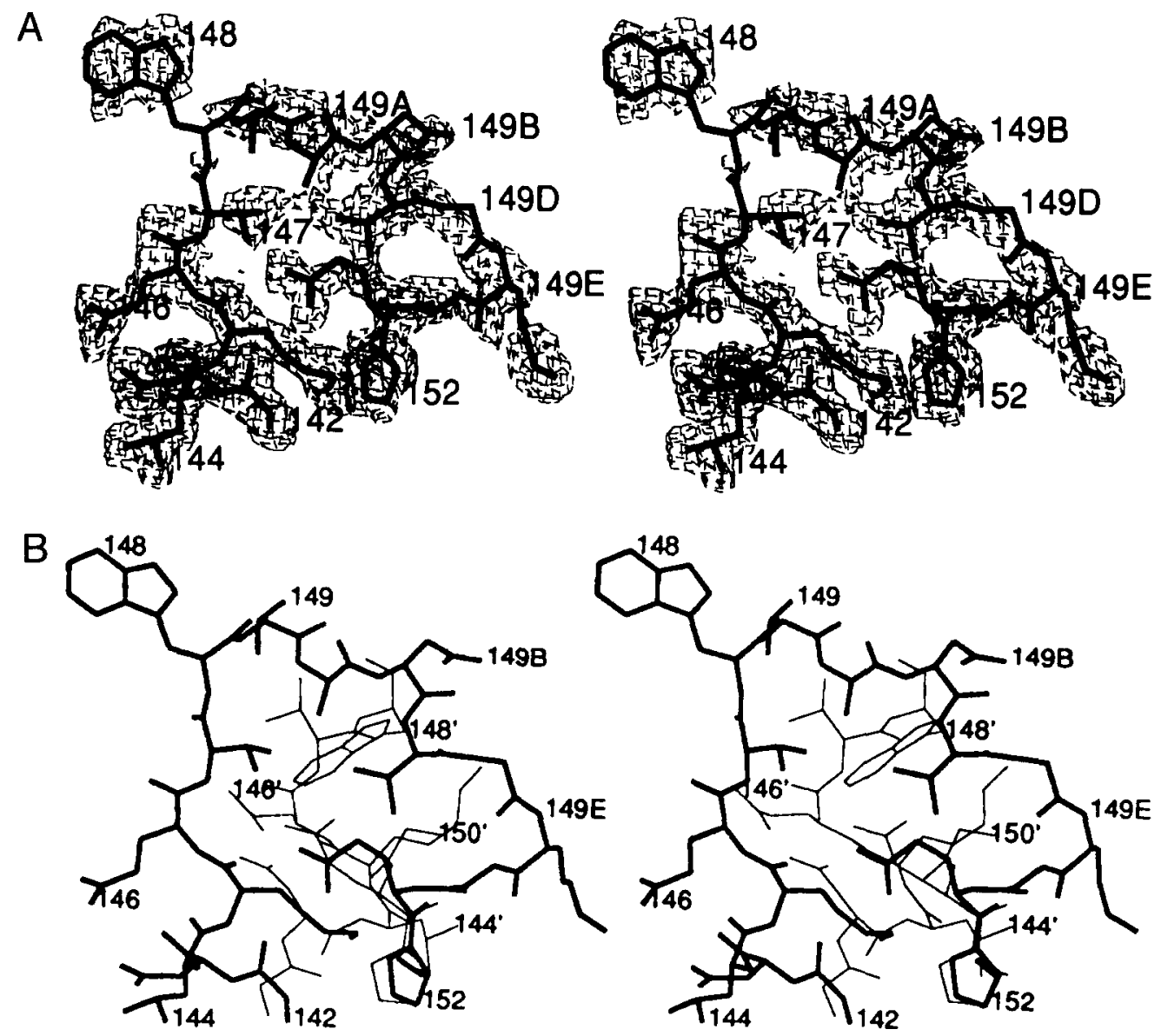

Fig. 7. Final $2\left|F_{o}\right|-\left|F_{c}\right|$ electron density map of the $\gamma$-autolysis loop region (Gly 142-Pro 152) of Pre2 and stereo view of

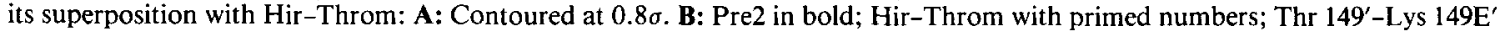
of Hir-Throm disordered.

of the Pre2 molecule ( $28 \AA^{2}$, which is comparable to HirThrom; Table 9), the difference must be due to a greater degree of disorder rather than increased thermal motion corresponding to an additional RMS displacement of $0.45 \AA$. The existence of good electron density for the region further suggests that a fairly high percentage of a principal folding conformer must exist along with a lesser fraction of different, but similar, conformations rather than a uniform distribution of different conformations. The former distribution would also produce an increasing effect on $B$-values. The C-terminal of hirudin (Rydel et al., 1991) and hirugen itself (Skrzypczak-Jankun et al., 1991; and the present work) binding in the fibrinogen recognition exosite of thrombin also have large $B$-values compared to the enzyme but show good electron density. In these cases, a skewed distribution with a principal binding conformation is the likely source of the effect. An alternative rationalization would be partial occupancy of the binding site in crystals; this is, however, inconsistent with the extraordinarily tight binding constants of the ligands.

Comparisons of the structures of chymotrypsinogen and chymotrypsin also reveal large differences in the conformations of all 4 segments of the activation domain (Freer et al., 1970; Wang et al., 1985). The comparisons were additionally complicated be- cause there are 2 independent molecules of chymotrypsinogen in one crystal form that showed differences in conformations due to crystal packing (Leu 33-Thr 37 loop, undefined in one molecule; Gly 142-Asp 153; Gly 216-Ser 221, different conformations) (Wang et al., 1985). Trigonal crystals of trypsinogen and trypsin are isomorphous but the activation domain of trypsinogen is completely disordered (Bode \& Huber, 1978). The disorder persists at low temperatures (Singh et al., 1980) but did not affect the resolution of the position of a mercurated, reduced Cys 191-Cys 220 disulfide (Walter et al., 1982). The results of these structural studies and that of Pre 2 all point to a flexible and tenuously conformed activation domain. Whether the mobility of the domain is from strain or other factors, it is undeniably poised to undergo change at the Arg 15-Ile 16 cleavage provocation.

A number of hydrogen bonding and ion pair changes occur with the reorganization of the activation domain of Pre2. A comparison of likely hydrogen bonds in Pre 2 and Hir-Throm is summarized in Table 2. Many of these have already been mentioned and discussed. The activation domain of Pre 2 has 3 salt bridges and one is lost on activation to thrombin; however, 3 new ion pairs are generated in the enzyme, one of which is doubly hydrogen bonded (Arg 187-Asp 222, Table 2). 
Table 3. Comparison of the conformations of Factor $X a$ around the cleavage site of Pre 2 and the $\beta$-cleavage site of $\alpha$-thrombin with BPTI (Pro 13-Arg 17) in the $B P T I-t r y p s i n$ complex and the Arg 15-Ile 16 cleavage site with respect to chymotrypsinogen ${ }^{\mathrm{a}}$

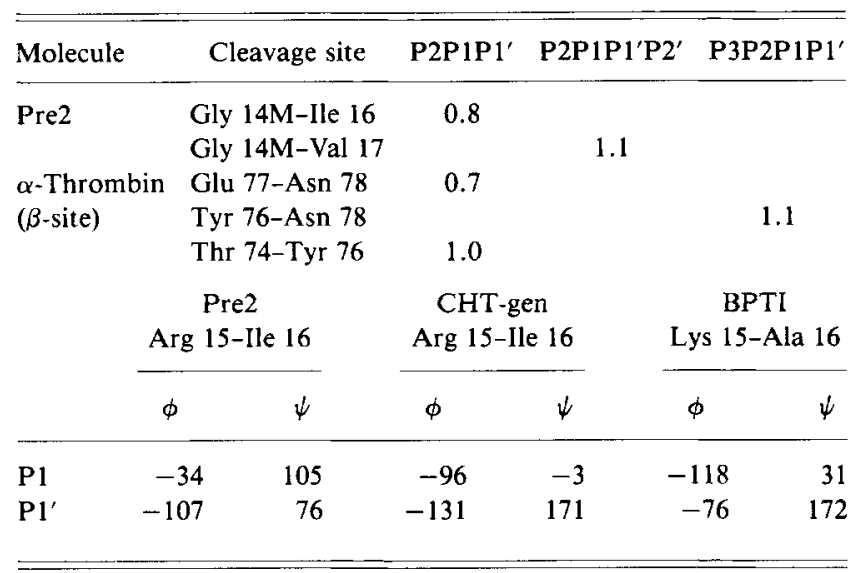

${ }^{\text {a }} \mathrm{RMS} \Delta$ in $\AA ; \phi, \psi$, in deg; CHT-gen, chymotrypsinogen.

\section{Active site changes in thrombin with exosite binding}

The structure of Hir-Throm was optimally superposed to the structure of monoclinic PPACK-Throm after rotation and translation $\left(-0.91^{\circ}, 0.18 \AA\right)$ with an RMS difference of $0.25 \AA$ for $270 \mathrm{C}_{\alpha}$-atoms; the corresponding difference between the monoclinic and orthorhombic (Bode et al., 1992) forms of PPACK-Throm is $0.29 \AA$, whereas the RMS deviation for 201 positions $(74 \%$ ) with differences less than $0.25 \dot{A}$ between $\mathrm{Hir}-$ Throm and monoclinic PPACK-Throm is $0.15 \AA$. In both HirThrom and monoclinic PPACK-Throm, the $\mathrm{N}$-terminal binding regions of the fibrinogen binding exosite make close contacts between neighboring molecules related by a 2 -fold rotation axis. The side chain of Lys 81 has different conformations in the 2 structures. In the Hir-Throm, it makes a hydrogen bond to a water molecule (Lys $81 \mathrm{NZ}-\mathrm{O}_{\mathrm{w}} 475,2.8 \AA$ ) that bridges to an oxygen atom of the sulfate of Tyr 63 of hirugen (Tyr 63') $\left(\mathrm{O}_{\mathrm{w}}\right.$ 475-Tyr 63'O13, 3.0 A). In PPACK-Throm, it is exposed to solvent. In the originally reported Hir-Throm structure (SkrzypczakJankun et al., 1991), Lys 81 was suggested to have 2 alternate conformations, one of which is involved in ion pair formation with the sulfate of Tyr 63'. Except for these differences, the fibrinogen binding exosite is very similar in the 2 structures (Table 4). A superposition of the exosites of Hir-Throm (including hirugen) and PPACK-Throm is shown in Figure 8 and Kinemage 2, from which it can be seen that the exosite does not undergo a conformational change with binding of hirugen.

The largest differences between Hir-Throm and PPACKThrom are in the active site region (Table 4; Figs. 9, 10; Kinemage 2). Although the differences of the backbone atoms are not very large, their average RMS deviation of $0.55 \AA$ is about $3.7 \sigma$ of the remainder of the structure. The difference electron density between the 2 structures reflects the changes most dramatically (Fig. 9). The deviations in the backbone in the active site increase from each end of the Ala 190-Gly 197 2-turn stretch toward the middle and reach a maximum of around $1.0 \AA$ near the Glu 192 position (Figs. 9, 10). This segment of peptide has 2 well-defined back-to-back type II $\beta$-bends (Venkatachalam, 1968; Crawford et al., 1973) in both molecules formed by Cys 191-Asp 194 and Asp 194-Gly 197. The plane of the first turn is at right angles to the second and both bends have a glycine resident at the third residue so the hydrogen bonding patterns of the two are similar: the plane of the amide between the second and third residues is flipped so that the carbonyl points toward the side chains. The first bend undergoes the largest shift with the binding of hirugen (Table 3 ). It moves as a rigid body and expands the space in the active center and the immediate vicinity of the catalytic site (Figs. 9, 10).

Only small changes, with differences of less than $0.3-0.4 \AA$, occur between Hir-Throm and PPACK-Throm at His 57 and between Pro 60B-Asp 60E of the active site region (Table 4). This is clearly not so for the negatively charged center of the S1 specificity site side chain of Asp 189 and the main and side chains of the loop between Arg 221 A and Gly 223. The Asp 189 side group moves away from the incoming guanidinium group of the arginyl of PPACK, as does the Arg 221A-Gly $223 \mathrm{seg}$ ment (Fig. 9). This expansion appears to be directly related to steric effects of active site inhibitor binding.

The side chain of Glu 192 has different conformations in the 2 structures (Figs. 9, 10; Kinemage 2). In PPACK-Throm, it bends around and points toward the specificity pocket, whereas in Hir-Throm, it is in an extended configuration pointing out toward solvent. This acidic residue is a glutamine in trypsin and is most likely related to the broader selectivity of the enzyme.

Table 4. Active site and exosite differences (RMS) between Hir-Throm and PPACK-Throm ${ }^{\mathrm{a}}$

\begin{tabular}{|c|c|c|c|c|}
\hline Region & All atoms $(\AA)$ & $\operatorname{Main}(\AA)$ & Side $(\AA)$ & Sulfur $(\dot{A})$ \\
\hline Fibrinogen exosite ${ }^{\mathrm{b}}$ & $0.67(247)$ & $0.24(84)$ & $0.88(135)$ & - \\
\hline Active site $(10 \AA \text { sphere })^{c}$ & $0.76(245)$ & $0.36(102)$ & $1.05(109)$ & $0.27(3)$ \\
\hline Catalytic triad $^{d}$ & $0.39(24)$ & $0.27(9)$ & $0.47(12)$ & - \\
\hline Cys 191-Asp 194 (type II, $\beta$-bend) & $2.00(27)$ & $0.70(12)$ & $3.00(11)$ & $0.45(1)$ \\
\hline Asp 194-Gly 197 (type II, $\beta$-bend) & $0.41(22)$ & $0.39(12)$ & $0.44(6)$ & - \\
\hline 60 Insertion loop (Tyr 60A-Thr I) & $0.55(83)$ & $0.33(27)$ & $0.67(47)$ & - \\
\hline
\end{tabular}

${ }^{a}$ Number of atoms in comparison in parentheses.

b Leu 33-Leu 41; Arg 67-Lys 81; Lys 109-Lys 110.

c Leu 41-Gly 43; Ala 56-Cys 58; Glu 97A-Asp 102; Thr 139-Glu 146; Asp 189-Gly 197; Ser 214-Gly 219.

${ }^{d}$ His 57, Asp 102, Ser 195. 


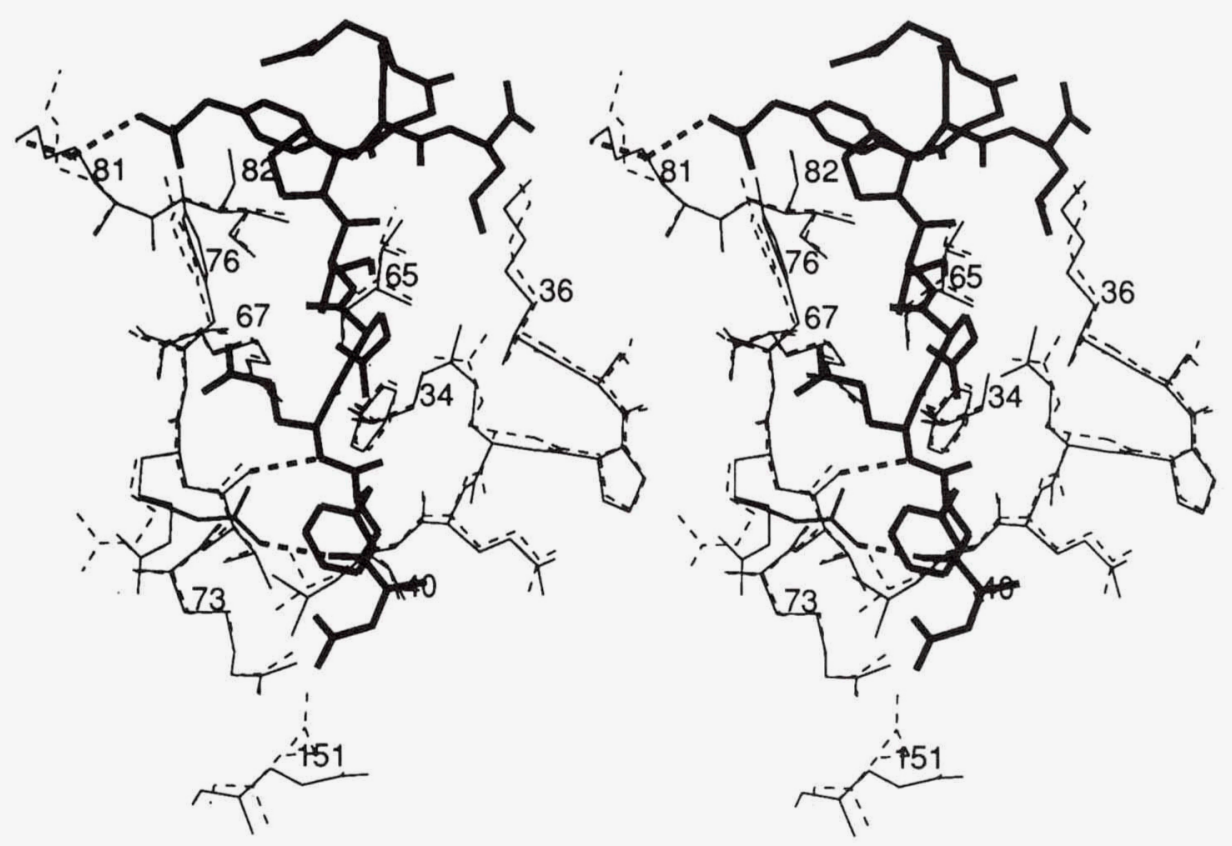

Fig. 8. Stereo view of superposition of Hir-and PPACK-Throm in the fibrinogen recognition exosite. Hirugen in bold, HirThrom in thin lines and PPACK-Throm in broken; hydrogen bonds in bold broken lines.

Acid residues at the $\mathrm{P} 3$ position of thrombin substrates are known to be inhibitory (Erhlich et al., 1990). However, thrombin becomes efficient in cleaving such peptides when accompanied by binding at the fibrinogen exosite (protein $\mathrm{C} /$ thrombomod- ulin [Esmon, 1989]; thrombin platelet receptor [Shaun Coughlin, pers. comm.]). A Glu $192 \rightarrow$ Gln mutation in thrombin has been found to mimic the catalytic changes produced by thrombomodulin (Le Bonniec \& Esmon, 1991). The extended Glu 192

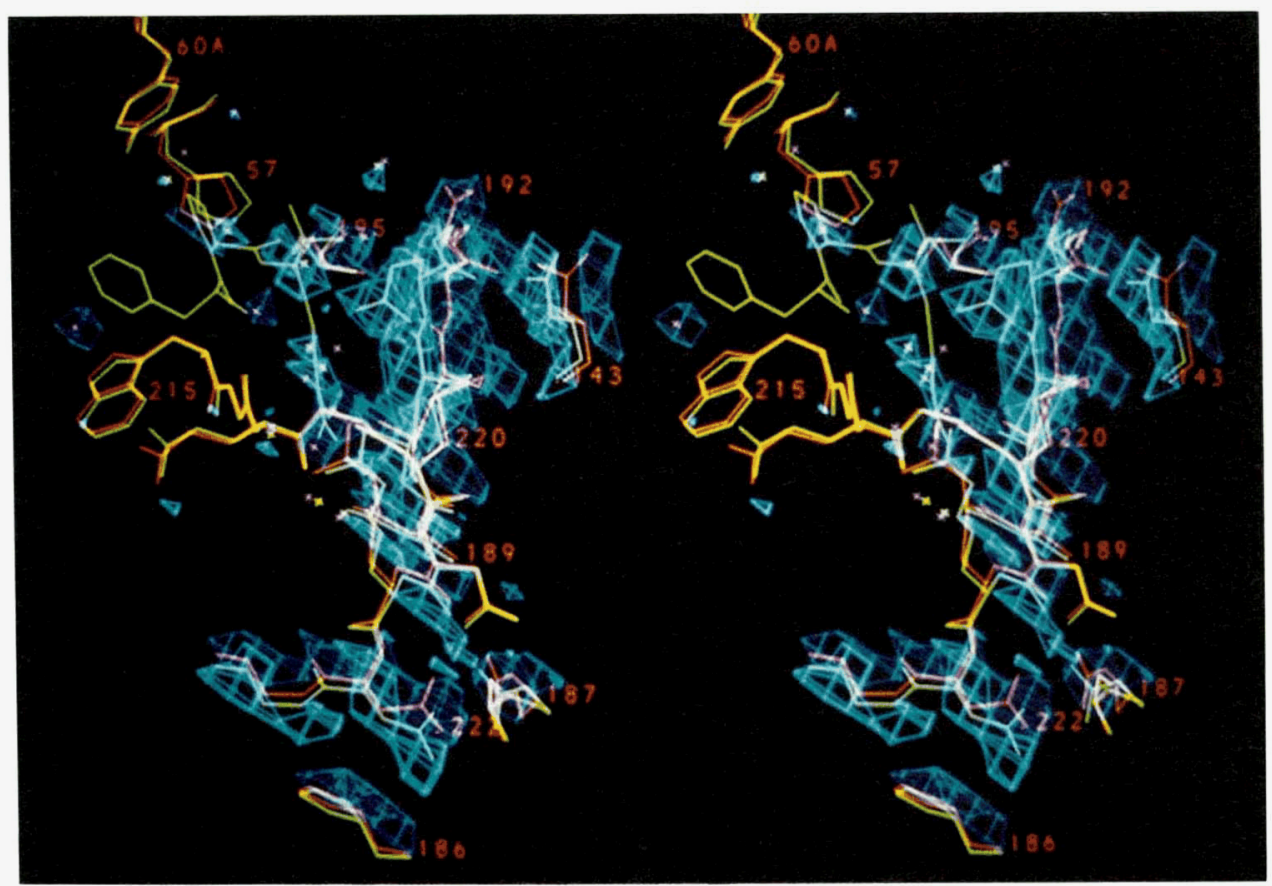

Fig. 9. Stereo view of the difference electron density between Hir-Throm and PPACK-Throm in the active site. Calculated with Fourier coefficients $\left\{\left|F_{\mathrm{HT}}\right| \exp \left(-i \alpha_{\mathrm{HT}}\right)-\left[\left|F_{\mathrm{PT}}\right| \exp \left(-i \alpha_{\mathrm{PT}}\right)-\left|F_{\mathrm{P}}\right|_{\mathrm{c}} \exp \left(-i \alpha_{\mathrm{P}}\right)\right]\right\}$, where HT and PT are Hir-Throm and PPACK-Throm, respectively, and $\left|F_{\mathrm{P}}\right|_{\mathrm{c}}$ and $\alpha_{\mathrm{P}}$ are the calculated amplitude and phase of PPACK; contoured at $\pm 3 \sigma$; dark blue, positive; light blue, negative; red, Hir-Throm; yellow, PPACK-Throm; green, PPACK. 

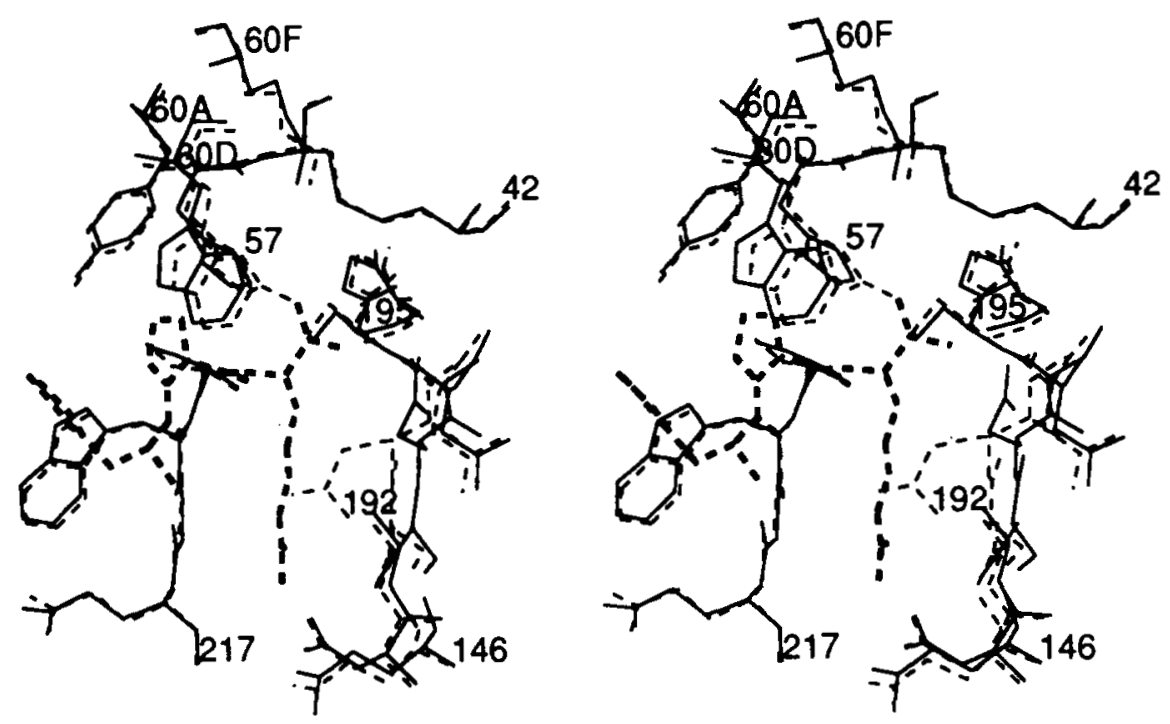

Fig. 10. Stereo view of superposition of Hir- and PPACK-Throm in the active site region. Hir-Throm in solid; PPACK-Throm in broken; PPACK in bold broken line.

conformation, distancing negative charge from the binding region, therefore, appears accommodating to the binding of substrate with a negative charge, at least, from these 2 observations, at the $\mathrm{P} 3$ position.

The electron density of Glu 192 is not always defined in different inhibitor complexes of thrombin. The conformations of Glu 192 in structures where it is unambiguous are given in Table 5 . The extended conformation (Fig. 9), or a poorly defined one is generally associated with fibrinogen exosite binding. The $\chi_{1}$ and $\chi_{2}$ angles of the bent Glu 192 conformation (Fig. 9) accompanying active site binding are more consistent ( $\chi_{3}$ corresponds to the orientation of the carboxylate group, which is usually difficult to fix unequivocally in the electron density). The bent conformation appears to be the result of binding at the active site because in the ternary complexes of Hir-Throm with cyclotheonamide (Maryanoff et al., 1993) or with DAPA (Mathews \& Tulinsky, 1994), Glu 192 has a bent conformation even though the complexes were prepared by adding the active site inhibitor to Hir-Throm (Table 5). Thus, active site binding can change the Glu 192 conformation of Hir-Throm. However, a degree of caution is prudent here because this conformation may not be that of native $\alpha$-thrombin and may be the result of PPACK binding. Chymotryptic cleavage of the $\gamma$-autolysis loop is known to be significantly impaired by PPACK binding (Parry et al., 1993).

In order to resolve this issue, isomorphous crystals of the ternary thrombin complex with PPACK in the active site and hirugen in the exosite were also prepared (hirugen added to PPACK-Throm). The diffraction data were measured (isomorphous with Hir-Throm) and the structure was refined at $2.5 \AA$ resolution $(R=13.8 \%)$. Comparison of the ternary complex structure with that of isomorphous PPACK-Throm revealed absolutely no differences in the active site region, indicating that hirugen is not capable of inducing a conformational change when the active site is occupied (Table 5). A comparison of the active site region of monoclinic and orthorhombic (Bode et al., 1992) PPACK-Throm also showed no significant differences, further indicating that crystal packing is not influencing the conformation of the active site.

A final observation of note in Table $S$ is that the ternary HirThrom complexes with CV863 and thrombin platelet receptor peptide show Glu 192 in an exosite binding conformation even though there is binding at the active site. In the case of CV863, hirugen was added to the inhibited thrombin, whereas the receptor peptide was treated with Hir-Throm, which cleaved the peptide, liberated the LDPR sequence that subsequently bound

Table 5. The conformation of Glu 192 in various inhibitor complexes of thrombin

\begin{tabular}{|c|c|c|c|c|}
\hline Complex & $\chi_{1}$ & $\chi_{2}$ & $x_{3}$ & $\begin{array}{l}\text { Order of ternary } \\
\text { complex formation }\end{array}$ \\
\hline $\operatorname{PPACK}(\mathrm{M})$ & -71 & 68 & -165 & - \\
\hline $\operatorname{PPACK}(O)^{\mathrm{a}}$ & -81 & 70 & -142 & - \\
\hline PPACK-Hir & -73 & 61 & -43 & PPACK-Throm + Hir \\
\hline Hirulog $1^{b}$ & -72 & 49 & -113 & - \\
\hline DAPA-Hir & -72 & 74 & -118 & $\mathrm{Hir}+\mathrm{DAPA}$ \\
\hline Cyclo $\mathrm{T}-\mathrm{Hir}^{\mathrm{d}}$ & -78 & 68 & -102 & Hir + Cyclo T \\
\hline PPACK-CV768 & -74 & 75 & -149 & PPACK-Throm + CV768 \\
\hline Hir & -153 & -151 & -241 & - \\
\hline Hirullin $^{f}$ & -161 & -230 & -166 & - \\
\hline LDPR-Hir ${ }^{\mathrm{g}}$ & -141 & -155 & -155 & Hir-Throm + LDPR \\
\hline$C V-863^{h}$ & -99 & -148 & -250 & Throm-CV863 + Hir \\
\hline Hirudin $^{i}$ & -39 & -151 & -311 & - \\
\hline
\end{tabular}

${ }^{\text {a }}$ Bode et al. (1992).

b Skrzypczak-Jankun et al. (1991).

c Mathews and Tulinsky (1994).

d Cyclotheonamide A, Maryanoff et al. (1993).

'Ace-FLLRNPNDKYEPFWEDEEKamide, Mathews et al. (1994).

f Qiu et al. (1993).

g LDPR-Throm-Hir, Mathews et al. (1994).

h BOC-DPR(CO-CO)-phenethyl, unpublished results of the laboratory.

i Rydel et al. (1991). 
Table 6. Water molecules in the active site regions of Hir-Throm and PPACK-Throm

\begin{tabular}{lccccccc}
\hline \hline & \multirow{3}{*}{ Hir-Throm } & & \multicolumn{3}{c}{ PPACK-Throm } \\
\cline { 1 - 4 } $\mathrm{O}_{\mathrm{w}}$ & Occup & $B\left(\AA^{2}\right)$ & $\Delta(\AA)^{\mathrm{a}}$ & $\mathrm{O}_{\mathrm{w}}$ & Occup & $B\left(\AA^{2}\right)$ \\
\hline 423 & 1.00 & 25 & 0.5 & 417 & 1.00 & 30 \\
$429^{\mathrm{b}}$ & 1.00 & 25 & 0.4 & $407^{\mathrm{b}}$ & 1.00 & 18 \\
$448^{\mathrm{b}}$ & 0.91 & 26 & & & & \\
$462^{\mathrm{b}}$ & 0.82 & 29 & & & & \\
466 & 0.80 & 29 & 0.3 & 408 & 1.00 & 17 \\
477 & 0.76 & 34 & & & & \\
478 & 0.75 & 23 & & & & \\
494 & 0.71 & 37 & 0.5 & 521 & 0.64 & 43 \\
$519^{\mathrm{b}}$ & 0.62 & 25 & & & & \\
555 & 0.54 & 28 & & & & \\
556 & 0.53 & 21 & & & & \\
578 & 0.50 & 32 & 1.2 & 536 & 0.60 & 34 \\
580 & 0.50 & 22 & & & & \\
588 & 0.50 & 17 & 0.9 & 502 & 0.70 & 41 \\
$592^{\mathrm{b}}$ & 0.50 & 23 & 1.0 & $428^{\mathrm{b}}$ & 0.98 & 22 \\
& & & & 427 & 0.99 & 35 \\
& & & & 496 & 0.72 & 11 \\
& & & & 504 & 0.69 & 34 \\
& & & & 544 & 0.58 & 27 \\
& & & & 545 & 0.58 & 32
\end{tabular}

${ }^{a}$ Shift in position between Hir-Throm and PPACK-Throm.

${ }^{\mathrm{b}}$ In $\mathrm{S} 1$ specificity site.

in the active site closely resembling PPACK (Mathews et al., 1994). Therefore, LDPR did not change the Glu 192 conformation the way cyclotheonamide and DAPA can and the extended Glu 192 conformation was maintained. This could be the result of the presence of an aspartate at the $\mathrm{P} 3$ position. The same argument is applicable to CV863 because it also has an aspartate at the $\mathrm{P} 3$ position. All of this suggests that thrombomodulinthrombin activation of protein $\mathrm{C}$ may proceed faster because thrombomodulin exosite binding to thrombin produces the ex- tended conformation, which is more amenable to the presence of a negative charge at the S3 subsite. Although it appears fairly certain that the bent conformation results from a conformational change that accompanies active site binding of substrates lacking an acid group at P3, nonetheless, it is also remotely possible that it is the conformation native to $\alpha$-thrombin.

There are about 15 water molecules in the active site region of Hir-Throm and although 8 are expelled with PPACK binding, somewhat surprisingly, there are still 12 water molecules in the active site region of PPACK-Throm (Table 6). This is because the solvent-accessible surface of the PPACK molecule is covered with a layer of 5 new water molecules $\left(O_{w}=427,496\right.$, 504, 544, 545; Table 6). Two of these make significant interactions between PPACK and thrombin: D-Phe $1^{\prime} \mathrm{N}-\mathrm{O}_{\mathrm{w}} 427$, $2.9 \AA$; Gly $219 \mathrm{~N}-\mathrm{O}_{\mathrm{w}} 427,2.5 \AA$ and $\mathrm{D}-\mathrm{Phe} 1^{\prime} \mathrm{N}-\mathrm{O}_{\mathrm{w}}$ 496, 3.1 $\AA$; $\mathrm{O}_{\mathrm{w}}$ 496-Pro 2'O, $2.5 \AA$; $\mathrm{O}_{\mathrm{w}}$ 496-Gly 192OE1, $2.6 \AA$. Another water in PPACK-Throm $\left(\mathrm{O}_{\mathrm{w}} 504\right)$ bridges Glu 1460 and Glu 192OE2 (3.1 and $2.7 \AA$, respectively). The latter 2 waters may be instrumental in stabilizing the bent conformation of Glu 192.

There are 5 water molecules in the S1 specificity site of HirThrom and 3 are not present with PPACK binding (Table 6). Four of them form an intricate hydrogen bonding network among themselves and between Asp 189OD2 and Gly 2190 (Fig. 11). On binding PPACK, the network is disrupted by the arginyl guanidinium group of PPACK, which forces out $\mathrm{O}_{w} 448, \mathrm{O}_{w} 462$, and $\mathrm{O}_{w} 519$. These are relatively weakly interacting with other water molecules and only form 1 or no hydrogen bonds with thrombin $\left(\mathrm{O}_{\mathrm{w}} 448-\mathrm{Gly} 2190, \mathrm{O}_{\mathrm{w}} 462-\mathrm{Asp} 1890 \mathrm{OD} 2\right)$. The waters remaining in PPACK-Throm are $\mathrm{O}_{w} 407$ and $\mathrm{O}_{\mathrm{w}} 428$ and they (1) bridge Arg $3^{\prime} \mathrm{NH} 1$ (3.1 $\AA$ ) and Phe $227 \mathrm{O}$ (3.1 $\AA$ ); and (2) Arg 3'NE (2.8 ̊̊), Glu 192OE1 (2.6 $)$, and Gly $219 \mathrm{~N}(2.7 \AA)$, respectively. It is noteworthy that the $\mathrm{O}_{w} 428$ position doubles in occupancy with PPACK binding but shifts about $1.0 \AA$ from the $\mathrm{O}_{\mathrm{w}} 592$ in Hir-Throm.

One of the most significant water molecules $\left(\mathrm{O}_{w} 423\right)$ is not only conserved in both structures, but it also has the same 3 hydrogen bonding interactions (with Glu 2170, $\operatorname{Arg} 221 \mathrm{AN}, \mathrm{O}_{\mathrm{w}}$ 494 or, $\mathrm{O}_{\mathrm{w}} 521$ in PPACK-Throm). The $\mathrm{O}_{\mathrm{w}} 494$ molecule hydrogen bonds with Asp 189OD1 (2.7 $\AA$ ), an interaction that is preserved in PPACK-Throm, but it additionally hydrogen

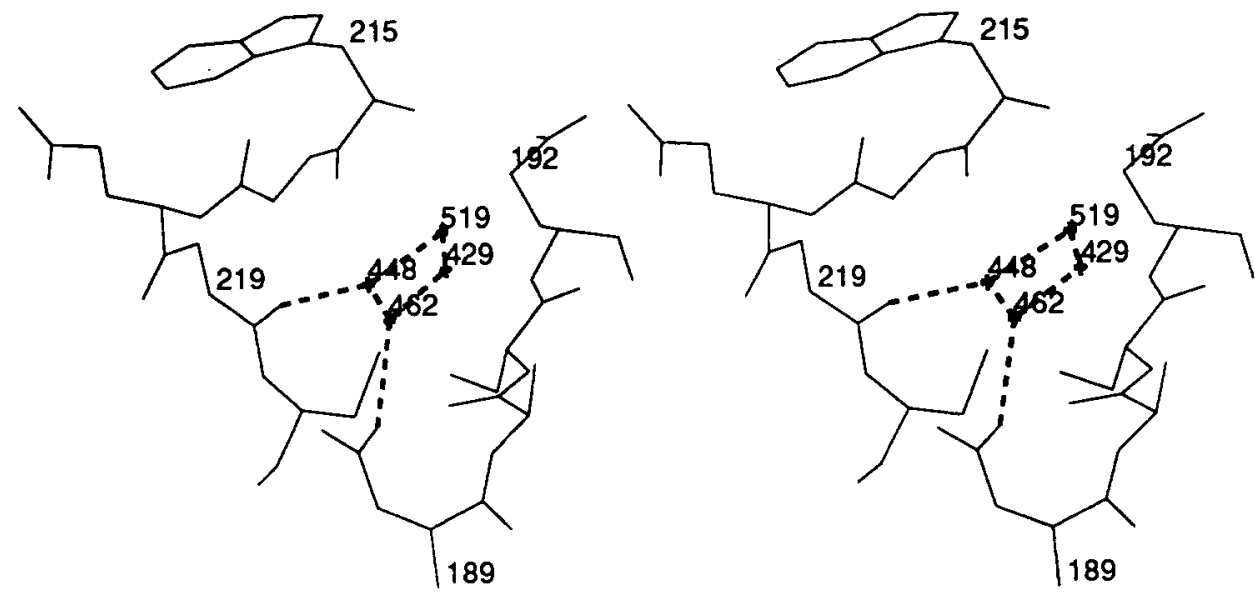

Fig. 11. Stereo view of the water cluster in the S1 specificity site of Hir-Throm. Water molecules designated by asterisks; hydrogen bonds by broken lines. 
bonds with Arg $3^{\prime} \mathrm{NH} 2(2.7 \AA)$ of the inhibitor. Another highly significant conserved water molecule $\left(\mathrm{O}_{\mathrm{w}} 466\right)$ bridges Tyr 60A $\mathrm{OH}(3.0 \AA)$ and $\operatorname{Trp} 960$ (2.5 $\AA$ ). The 2 remaining conserved waters $\left(\mathrm{O}_{w} 578, \mathrm{O}_{w} 588\right)$ are less definite in their interactions and their occupancy parameters are lower (Table 6); $\mathrm{O}_{\mathrm{w}} 588$ appears to move by about $0.9 \AA$ and form a hydrogen bond with Arg 3'O in PPACK-Throm. This could be the reason for the increase in the occupancy of $\mathrm{O}_{w} 502$ in the latter structure. Two other displaced water molecules $\left(\mathrm{O}_{\mathrm{w}} 477, \mathrm{O}_{\mathrm{w}} 556\right)$ are of note: $\mathrm{O}_{\mathrm{w}} 477$ hydrogen bonds with $\mathrm{His} 570$ and Lys 60FNZ of the S1' subsite (Qiu et al., 1992) and $O_{w} 556$ is at the oxyanion hole position (Henderson, 1970; Robertus et al., 1972) and hydrogen bonds with amido nitrogen atoms of Gly 193 and Ser 195 of the active site.

\section{Summary}

As more or less expected from previous results obtained with chymotrypsinogen-chymotrypsin, in Pre 2 there are 4 peptide segments forming the so-called activation domain that differ markedly in conformation and position to those in the activated enzyme thrombin: Pro 186-Asp 194, Gly 216-Gly t223, Gly 142Pro 152, and the Arg 15-Ile 16 Factor Xa cleavage region.

The active site residues are already in an active conformation in Pre2, as in chymotrypsinogen, with the exception of the oxyanion hole-forming segment.

Although Pre2, like tissue-type plasminogen activator, does not possess a "zymogen triad" of Ser 32, His 40, Asp 194 as does chymotrypsin, so that Asp 194 is not fixed by exceptionally strong hydrogen bonds, this does not lead to premature catalytic activity.

Hirugen is found to bind at the fibrinogen recognition exosite with a virtually identical conformation as that observed for the active enzyme. Experimental solution data are in conflict on this point for pre2: hirugen binding is indicated but not binding of macromolecular substrates.

The changes that occur in the active site that affect the kinetics of chromogenic substrate hydrolysis on binding to the fibrinogen recognition exosite have been shown to be primarily due to changes in the Ala 190-Gly 197 segment and possibly due to the conformation of Glu 192. The latter extends to solvent in hirugen-thrombin compatible with binding of substrates having an acidic sidegroup in the $\mathrm{P} 3$ position.

When the active site is "free" (water filled), hirugen binding expands the region. When the active site is occupied by substrate or an inhibitor, Glu 192 is in a bent conformation over the specificity pocket, except in the case when $\mathrm{P} 3$ is an acidic residue. The conformation is then Hir-Throm-like.

PPACK expels 8 water molecules from the active site, but the inhibitor complex is resolvated with 5 other water molecules.

\section{Materials and methods}

\section{Isolation of human pre2}

A prothrombin fragment composed of residues Asp 263-Glu 579 was generated by cleavage of human prothrombin with a purified snake venom protease from $N$. nigricollis. The venom protease was purified from crude venom using gel filtration on Sephadex G-100 and chromatography on sulfopropyl Sephadex (Hassan, 1985). Fifty milligrams of human prothrombin in
$20 \mathrm{mM}$ Tris, $105 \mathrm{mM} \mathrm{NaCl}, 2 \mathrm{mM} \mathrm{CaCl}_{2}, \mathrm{pH} 7.4$, was made $1 \mathrm{mM}$ DFP and dialyzed against the same buffer without DFP. The final prothrombin concentration was adjusted to 1.1 $\mathrm{mg} / \mathrm{mL}$ and treated with $1 / 1,000(\mathrm{w} / \mathrm{w})$ of purified $N$. nigricollis enzyme at $37^{\circ} \mathrm{C}$ for $8 \mathrm{~h}$. The reaction was quenched with EDTA ( $5 \mathrm{mM}$ final concentration) and PPACK ( $50 \mu \mathrm{M}$ final concentration). The sample was dialyzed against $0.025 \mathrm{M}$ sodium phosphate, 5 mM EDTA, pH 6.5, and chromatography carried out as described by Mann (1976). The human pre2 analogue was judged to be pure by SDS-PAGE.

\section{Crystallization}

The pre2-hirugen complex was made with lyophilized pre 2 by adding 10-fold molar excess of hirugen to a solution of about $7 \mathrm{mg} / \mathrm{mL}$ pre 2 in $0.375 \mathrm{M} \mathrm{NaCl}$ and $0.05 \mathrm{M}$ sodium phosphate buffer, $\mathrm{pH}$ 7.3. Crystals were grown by the vapor diffusion hanging drop method. Typically, the protein complex was mixed with an equal volume of the precipitant solution containing $0.1 \mathrm{M}$ sodium phosphate, pH 7.3, 27\% PEG $8 \mathrm{~K}$, and $1 \mathrm{mM}$ $\mathrm{NaN}_{3}$. These conditions are also similar to those used to crystallize the Hir-Throm complex (Skrzypczak-Jankun et al., 1991). Small rectangular-shaped crystals grow within a couple of weeks. Macroseeding techniques were required to enlarge the crystals (Thaller et al., 1985). The crystals tend to dissolve in 2-3 weeks but can be stored for much longer periods by increasing the PEG concentration to $32 \%$ and keeping the crystals at $4{ }^{\circ} \mathrm{C}$. The crystal used for intensity data collection was $0.6 \times$ $0.2 \times 0.1 \mathrm{~mm}$. The crystals are isomorphous with Hir-Throm and belong to the monoclinic space group $\mathrm{C} 2$ with unit cell dimensions of $a=72.85, b=71.32, c=72.63 \AA, \beta=101.1^{\circ}, 1$ molecule per asymmetric unit.

Crystals of Hir-Throm $(a=71.75, b=72.39, c=73.52 \AA$, $\beta=101.3^{\circ}$ ) were prepared as described elsewhere (SkrzypczakJankun et al., 1991). The monoclinic form of PPACK-Throm was obtained while attempting to prepare a complex of PPACKThrom with a Factor VIII peptide fragment (Ace-GEDFDIY DEDEN, where $Y$ is sulfated). A 10 -fold molar excess of the peptide was added to frozen PPACK-Throm $(1 \mathrm{mg} / \mathrm{mL}, 0.75 \mathrm{M}$ $\mathrm{NaCl}$ ), allowed to thaw, and concentrated to about $5 \mathrm{mg} / \mathrm{mL}$. Crystallization trials using conditions that produce orthorhombic PPACK-Throm (Bode et al., 1989; Skrzypczak-Jankun et al., 1989) surprisingly did not yield any crystals. A factorial search was made that produced crystals of similar morphology as HirThrom from $0.2 \mathrm{M}$ sodium acetate, $0.1 \mathrm{M}$ cacodylate, $\mathrm{pH} 6.5$, and $25 \%$ PEG $8 \mathrm{~K}$. X-ray examination showed the crystals were monoclinic and isomorphous with Hir-Throm and Pre2: $a=$ $70.97, b=72.50, c=72.57 \AA$, and $\beta=100.5^{\circ}$. Detailed X-ray analysis showed no evidence of the Factor VIII peptide binding to PPACK-Throm in the crystals. Because the same crystals grow without the Factor VIII peptide, the peptide does not behave like a crystallization additive, which often can affect crystal growth in unknown ways, to produce PPACK-Throm isomorphous with Hir-Throm.

\section{Intensity data collection/processing}

Intensities of the Pre 2 crystal were measured with an R-AXIS II imaging plate detector using $0.3-\mathrm{mm}$ collimated graphite monochromated $\mathrm{CuK}_{\alpha}$ radiation from a Rigaku RU200 rotating anode generator operating at $5 \mathrm{~kW}$ power with a fine focus 
Table 7. $R$-AXIS intensity data statistics of Pre2

\begin{tabular}{|c|c|c|c|c|c|c|c|}
\hline \multicolumn{5}{|c|}{ Shell } & \multicolumn{3}{|c|}{ Cumulative } \\
\hline $\begin{array}{l}\text { Resol } \\
\text { (A) }\end{array}$ & $\left\langle|F|^{2}\right\rangle$ & $\left\langle|F|^{2} / \sigma\right\rangle$ & $\begin{array}{l}(\%) \\
\text { Obs }\end{array}$ & $\underset{(\%)}{R_{\text {merge }}}$ & Obs & $(\%)$ & $R$-cum(\%) \\
\hline 15.00 & 860 & 26.1 & 66.7 & 2.3 & 50 & 66.7 & 2.3 \\
\hline 10.00 & 969 & 21.6 & 71.2 & 2.9 & 159 & 69.7 & 2.7 \\
\hline 7.50 & 627 & 19.7 & 81.5 & 3.4 & 406 & 76.5 & 3.0 \\
\hline 5.00 & 456 & 17.4 & 84.4 & 3.9 & 1,401 & 81.9 & 3.5 \\
\hline 3.50 & 541 & 15.3 & 89.0 & 4.7 & 4,181 & 86.5 & 4.3 \\
\hline 3.00 & 189 & 9.1 & 84.0 & 7.0 & 6,501 & 85.6 & 4.6 \\
\hline 2.75 & 102 & 5.9 & 76.9 & 9.6 & 8,220 & 83.6 & 4.9 \\
\hline 2.50 & 67 & 4.4 & 71.2 & 11.8 & 10,506 & 80.6 & 5.1 \\
\hline 2.25 & 45 & 3.1 & 61.4 & 14.6 & 13,427 & 75.4 & 5.4 \\
\hline 2.00 & 31 & 2.2 & 43.3 & 20.0 & 16,642 & 66.0 & 5.6 \\
\hline
\end{tabular}

filament $(0.3 \times 3.0 \mathrm{~mm})$. The crystal-plate distance was $75 \mathrm{~mm}$ and each frame was collected for $60 \mathrm{~min}$ with an oscillation range of $2.5^{\circ}$. The total scan range for the data collection was $75^{\circ}$, the average mosaic spread of a reflection was $0.55^{\circ}$ and the total exposure time was less than $35 \mathrm{~h}$. The unit cell was determined by auto-indexing (Higashi, 1990) and the processing of the raw data was carried out with the Rigaku R-AXIS data processing software package. A total of 23,973 observations with $|F|^{2}>1.0 \sigma$ were made of which 16,642 were unique reflections in the $15.0-2.0-\AA$ resolution range $\left(R_{\text {merge }}=5.6 \%\right)$. This corresponds to $66 \%$ of the total number of possible reflections; the completeness of the last resolution shell $(2.3-2.0 \AA)$ is $43 \%$. Some of the intensity data statistics and processing results are summarized in Table 7.

The Hir-Throm and monoclinic PPACK-Throm intensity data sets were measured with a Siemens X-1000 multiwire area detector using protocols similar to those described previously (Qiu et al., 1992). Independent data sets from 2 different crystals were measured for both Hir-Throm ( $83 \%$ at $2.3 \AA$ resolution) and PPACK-Throm (75\% at $2.4 \AA$ resolution). The $|F|^{2}$ values $\left(R_{\text {merge }}=3.1\right.$ and $3.5 \%$, Hir-Throm; 3.3 and $5.2 \%$, PPACK-Throm) were averaged after matching reflections to determine a scale factor and average $B$-value that produce nearly identical $|F|^{2}$ distributions. The $R$-values between the indepen- dent sets are $6.8 \%$ for 15,157 reflections of Hir-Throm and $5.4 \%$ for 13,404 reflections of PPACK-Throm. The $R$-value between Pre 2 and Hir-Throm is $28 \%\left(\Delta B\right.$ of $+9.0 \AA^{2}$ applied to Pre2), whereas that between PPACK-Throm and Hir-Throm is $22 \%(\Delta B=0)$.

\section{Structure refinement}

\section{Pre2}

The isomorphous structure of Hir-Throm (less hirugen) with an average $B$-factor of $30 \AA^{2}$ was taken as the starting model for pre2. A rigid body refinement with the program X-PLOR (Brünger, 1990) with data between 10.0 and $3.0 \AA$ A resolution began at a relatively high $R=42.5 \%$ but reduced to $36.2 \%$. The $\left|F_{o}\right|-\left|F_{c}\right|$ difference electron density map calculated with these phase angles showed negative density for Thr $1 \mathrm{H}-\mathrm{Glu} 1 \mathrm{C}$, Glu 14H-Gly 19, Gly 142-Glu 146, Gly 150-Pro 152, Lys 185 Asp 194, Trp 215-Lys 224, and Gln 244-Glu 247 (71 total residues) indicating that these segments, most of which correspond to the pre 2 activation domain, have different conformations from those of Hir-Throm. The regions (along with Ala 1B, Arg 14D-Leu 14G, and Trp 141) were removed from the model and the rigid body refinement was repeated, which gave a significantly better $R$-value of $32.8 \%$. Positional refinement with X-PLOR using 7,602 reflections $\left(|F|^{2}>1.0 \sigma\right)$ between 10.0 and $2.8 \AA$ resolution reduced $R$ to $25.9 \%$. Electron density maps calculated with $2\left|F_{o}\right|-\left|F_{c}\right|$ and $\left|F_{o}\right|-\left|F_{c}\right|$ were used to model 36 of the missing residues into the structure along with the inhibitor hirugen molecule bound in the fibrinogen recognition exosite (Table 8). The remainder of the missing Pre2 structure emerged in stages during refinement with PROLSQ and PROFFT and was included into calculations gradually. A summary of the progress and the refinement of the structure is given in Table 8.

Water molecules were located and added periodically in the refinement by examining $\left|F_{o}\right|-\left|F_{c}\right|$ maps in 2 different resolution ranges: $10.0-2.5 \AA$ and $7.5-2.5 \AA$. Larger peaks common to both and also the $2\left|F_{o}\right|-\left|F_{c}\right|$ maps that were within $4.0 \AA$ of protein atoms were usually selected as water molecules. The coordinates and occupancies (but not $B$-values) of water oxygen atoms were refined first along with protein coordinates and $B$-values; the occupancies were then held constant and the

Table 8. Progress of the structure determination and refinement of Pre2

\begin{tabular}{lccccc}
\hline Round & $\begin{array}{c}\text { Resolution } \\
\text { range }(\AA)\end{array}$ & $\begin{array}{c}\text { No. of } \\
\text { reflections }\end{array}$ & $R(\%)$ & $\begin{array}{c}\text { No. of } \\
\text { waters }\end{array}$ & Additional residues added \\
\hline 1 & $10.0-2.8$ & 7,602 & 25.9 & - & $\begin{array}{c}\text { Ala 1B-Glu 1C; Arg 14D-Tyr 14J; Ile 16-Gly 19; Trp 141-Glu 146; Pro 152; } \\
\text { Lys 185-Glu 186B; Asp 189-Asp 194; Trp 215-Cys 220; Lys 224; hirugen } \\
2\end{array}$ \\
\hline $10.0-2.8$ & 7,602 & 21.6 & - & $\begin{array}{l}\text { Thr 147; Gln 151; Gly 186C; Gly 188; Asp 221-Gly 223 } \\
3\end{array}$ \\
\hline & $10.0-2.5$ & 10,346 & 20.3 & 34 & Gly 1D-Thr 1H; Ile 14K-Arg 15; Trp 148-Ala 149A; Val 149C-Gly 150 \\
5 & $10.0-2.5$ & 10,346 & 18.1 & 120 & \\
6 & $9.0-2.2$ & 13,854 & 19.1 & 148 & Arg 187, Asn 149B, N-acetyl-glucosamine \\
7 & $8.0-2.0$ & 16,311 & 17.8 & $202^{\text {a }}$ & Gln 244-Glu 247 \\
& $8.0-2.0$ & $14,211^{\mathrm{b}}$ & 16.9 & 202 &
\end{tabular}

accupancies $>0.5$.

${ }^{b}\left|F_{o}\right|>3 \sigma$, with variable weights in refinement (see Table 9). 
Table 9. Target refinement parameters and statistics

\begin{tabular}{|c|c|c|c|c|}
\hline & Target $\sigma$ & Pre2 & $\begin{array}{l}\text { Hir-Throm } \\
\text { RMS } \Delta\end{array}$ & PPACK-Throm \\
\hline \multicolumn{5}{|l|}{ Distances $(\AA)$} \\
\hline Bond distance & 0.022 & 0.022 & 0.022 & 0.020 \\
\hline Angle distance & 0.035 & 0.053 & 0.052 & 0.050 \\
\hline Planar 1,4 distance & 0.050 & 0.058 & 0.059 & 0.058 \\
\hline \multicolumn{5}{|l|}{ Nonbonded distance $(\AA)$} \\
\hline Single torsion & 0.50 & 0.25 & 0.22 & 0.22 \\
\hline Multiple torsion & 0.50 & 0.35 & 0.28 & 0.30 \\
\hline Possible $\mathrm{H}$ bond & 0.50 & 0.30 & 0.28 & 0.30 \\
\hline \multicolumn{5}{|l|}{ Torsion angles (deg) } \\
\hline Planar & 3 & 4 & 4 & 4 \\
\hline Staggered & 15 & 25 & 21 & 22 \\
\hline Orthonormal & 20 & 34 & 28 & 28 \\
\hline Planar groups $(\AA)$ & 0.03 & 0.03 & 0.03 & 0.03 \\
\hline Chiral centers $\left(\AA^{3}\right)$ & 0.15 & 0.21 & 0.18 & 0.21 \\
\hline \multicolumn{5}{|l|}{ Thermal restraints $\left(\dot{\mathrm{A}}^{2}\right)$} \\
\hline Main-chain bond & 1.5 & 1.2 & 1.2 & 1.4 \\
\hline Main-chain angle & 2.0 & 2.1 & 1.9 & 2.3 \\
\hline Side-chain bond & 2.5 & 2.6 & 2.6 & 3.0 \\
\hline Side-chain angle & 3.0 & 3.7 & 3.5 & 4.2 \\
\hline Average bond angle (deg) & & 116.9 & 117.2 & 116.8 \\
\hline RMS deviation & & 2.8 & 2.7 & 2.8 \\
\hline Atoms/asymmetric unit & & 2,690 & 2,656 & 2,596 \\
\hline Water molecules ${ }^{\mathbf{a}}$ & & 202 & 204 & 194 \\
\hline$R$-factor $(\%)$ & & 16.9 & 14.0 & 13.9 \\
\hline Overall $B\left(\dot{A}^{2}\right)$ & & 30.6 & 27.7 & 27.6 \\
\hline Mean positional error $(\AA)^{b}$ & & 0.21 & 0.17 & 0.17 \\
\hline \multicolumn{5}{|c|}{ Diffraction pattern: $\sigma\left(\left|F_{o}\right|\right)=\mathrm{A}+\mathrm{B}[\sin (\theta) / \lambda-1 / 6]$} \\
\hline A & & 26 & 23 & 22 \\
\hline $\mathrm{B}$ & & -85 & -110 & -110 \\
\hline$\left\langle\left|F_{o}\right|-\left|F_{c}\right|\right\rangle$ & & 59 & 49 & 49 \\
\hline
\end{tabular}

accupancy $>0.5$.

${ }^{b}$ Luzzati (1952).

$B$-values of the water molecules were refined along with the protein for a few more cycles.

\section{Hir-Throm and PPACK-Throm}

The new, averaged data set of Hir-Throm was used to refine the originally reported Hir-Throm structure (SkrzypczakJankun et al., 1991) with PROLSQ and PROFFT. The refinement started with 7.0-2.8- $\AA$ data and an average $B$-value, but individual $B$-values were introduced shortly thereafter. The resolution was then extended to $2.5 \AA$ and water molecules were included. The water molecules were found and refined as described for the Pre2 structure. Finally, resolution was increased to its limit. The $R$-value began at $28.5 \%$ and ultimately converged to $14.0 \%$ (Table 9). The PPACK-Throm refinement was carried out in a similar fashion using the final Hir-Throm structure, less hirugen, as the starting model. With PPACK-Throm, additional restraints were introduced for the tetrahedral link of the methylene of PPACK to His 57NE2 and the hemiketal formed with the carbonyl carbon by Ser $1950 G$. The $R$-factor began at $27.6 \%$ and finally converged at $13.9 \%$. The final tar- get values and RMS deviations from model values of the 3 refined structures are given in Table 9.

The coordinates of Pre2 (1HAG), the new Hir-Throm structure (1HAH), and monoclinic PPACK-Throm (1HAI) have been deposited in the Brookhaven Protein Data Bank.

\section{Acknowledgments}

This work was supported by NIH grant HL43229 to A.T. and grants HL46703 and HL34575 to K.G.M. The $\alpha$ - and PPACK-Throm were gifts of Dr. John W. Fenton II and the hirugen came from Dr. John M. Maraganore. We thank Dr. V. Ganesh for assistance in the early stages of the work on Pre2, Dr. I.I. Mathews for measuring one of the data sets of PPACK-Throm, and M. Rand for his assistance in preparing the pre2 (Asp 263-Glu 579).

\section{References}

Arni RK, Padmanabhan K, Padmanabhan KP, Wu TP, Tulinsky A. 1993. Structures of the non-covalent complexes of human and bovine prothrombin fragment 2 with human PPACK-thrombin. Biochemistry $32: 4727-4737$ 
Bode W, Huber R. 1978. Crystal structure analysis and refinement of two variants of trigonal trypsinogen. FEBS Lett 90:265-268.

Bode W, Meyer I, Baumann U, Huber R, Stone SR, Hofsteenge J. 1989. The refined $1.9 \AA$ crystal structure of human $\alpha$-thrombin: Interaction with D-Phe-Pro-Arg chloromethyl ketone and significance of the Tyr-Pro-ProTrp insertion segment. EMBO $J$ 8:3467-3475.

Bode W, Turk D, Karshikov A. 1992. The refined $1.9 \AA$ X-ray crystal structure of D-Phe-Pro-Arg chloromethyl ketone-inhibited human $\alpha$-thrombin: Structure analysis, overall structure, electrostatic properties, detailed active site geometry and structure function relationships. Protein $\mathbf{S c}$ I:426-471.

Brünger AT. 1990. X-PLOR manual, version 2.1. New Haven, Connecticut: Yale University.

Chang JY. 1986. The structures and proteolytic specificities of autolysed human thrombin. Biochem J 240:797-802.

Chirgadze NY, Clawson DK, Gesellchen PD, Hermann RB, Kaiser RE Jr, Olkowski JL, Sall DJ, Schevitz RW, Smith GF, Shuman RT, Wery JP, Jones ND. 1992. The X-ray structure at $2.2 \AA$ resolution of a ternary complex containing human alpha-thrombin, a hirudin peptide (54-65) and an active site inhibitor. ACA Annual Meeting, Pittsburgh, Pennsylvania, August 9-14, 1992. Abstr PB33.

Church FC, Pratt CW, Noyes CM, Kalayanamit T, Sherill GB, Tobin RB, Meade JB. 1989. Structural and functional properties of human $\alpha$ thrombin, phosphopyridoxylated $\alpha$-thrombin and $\gamma_{\mathrm{T}}$-thrombin: Identification of lysyl residues in $\alpha$-thrombin that are critical for heparin and fibrin(ogen) interactions. $J$ Biol Chem 264:18419-18425.

Crawford JL, Lipscomb WN, Schellman CG. 1973. The reverse turn as a polypeptide conformation in globular proteins. Proc Natl Acad Sci USA $70: 538-542$.

Dennis S, Wallace A, Hofsteenge J, Stone SR. 1990. Use of fragments of hirudin to investigate the thrombin-hirudin interaction. Eur J Biochem 188:61-66.

Downing MR, Butkowski RJ, Clark MM, Mann KG. 1975. Human prothrombin activation. $J$ Biol Chem 250:8897-8906

Erhlich HJ, Grinnell BW, Jaskunas SR, Esmon CT, Yan SB, Bang NU. 1990. Recombinant human protein $C$ derivatives: Altered response to calcium resulting in enhanced activation by thrombin. EMBO J 9:2367-2373.

Esmon CT. 1989. The roles of protein C and thrombomodulin in the regulation of blood coagulation. $J$ Biol Chem 264:4743-4746.

Fenton JW II. 1981. Thrombin specificity. Ann NY Acad Sci 370:468-495.

Fenton JW II. 1986. Thrombin. Ann NY Acad Sci 485:5-15.

Fenton JW II, Fasco MJ, Stackrow AB, Aronson DL, Young AM, Finlayson JS. 1977. Human thrombins: Production evaluation, and properties of $\alpha$-thrombin. $J$ Biol Chem 252:3587-3598.

Freer ST, Kraut J, Robertus JD, Wright HT, Xuong NgH. 1970. Chymotrypsinogen: $2.5 \AA$ A crystal structure, comparison with $\alpha$-chymotrypsin, and implications for zymogen activation. Biochemistry 9:1997-2009.

Hassan MI. 1985. Selected proteolysis of prothrombin, factor V, factor VIII, and factor X with the venom proteases of Naja nigricollis and Cerastes cerastes. Cairo, Egypt: Ain Shams University.

Henderson R. 1970. Structure of crystalline $\alpha$-chymotrypsin. IV. The structure of indoleacryloy $1-\alpha$-chymotrypsin and its relevance to the hydrolytic mechanism of the enzyme. J Mol Biol 54:341-354.

Higashi T. 1990. Auto indexing of oscillation images. $J$ Appl Crystallogr $23: 253-257$.

Hortin GL, Trimpe BL. 1991. Allosteric changes in thrombin's activity produced by peptides corresponding to segments of natural inhibitors and substrates. J Biol Chem 266:6866-6871.

Hubbard SJ, Campbell SF, Thornton JM. 1991. Molecular recognition. Conformational analysis of limited proteolytic sites and serine proteinase protein inhibitors. $J \mathrm{Mol} \mathrm{Biol} \mathrm{220:507-530.}$

Hubbard SJ, Eisenmenger F, Thornton JM. 1994. Modeling studies of the changes in conformation required for cleavage of limited proteolytic sites. Protein Sci 3:757-768.

Huber R, Bode W. 1978. Structural basis of the activation and action of trypsin. Acc Chem Res 11:114-122.

Huber R, Kukla D, Bode W, Schwager P, Bartels K, Deisenhofer J, Steigemann W. 1974. Structure of the complex formed by bovine trypsin and bovine pancreatic trypsin inhibitor. II. Crystallographic refinement at $1.9 \AA$ resolution. $J$ Mol Biol 89:73-101.

Jones TA. 1982. Frodo: A graphics fitting program for macromolecules. In: Sayre D, ed. Computational crystallography. Oxford, UK: Clarendon. pp 303-317.

Karshikov A, Bode W, Tulinsky A, Stone SR. 1992. Electrostatic interactions in the association of proteins: An analysis of the thrombin-hirudin complex. Protein Sci 1:727-735.

Konno S, Fenton JW II, Villanueva GB. 1988. Analysis of the secondary structure of hirudin and the mechanism of its interaction with thrombin. Arch Biochem Biophys 267:158-166.
Krishnaswany S, Church WR, Nesheim ME, Mann KG. 1987. Activation of human prothrombin by human prothrombinase: Influence of factor $\mathrm{Va}$ on the reaction mechanism. $J$ Biol Chem 262:3291-3299.

Krstenansky JL, Broersman RJ, Owen TJ, Payne MH, Mao SJT. 1990. Development of MDL 28,050, a small stable antithrombin agent based on a functional domain of the leech protein, hirudin. Thromb Haemostasis $63: 208-214$.

Le Bonniec BF, Esmon CT. 1991. Glu-192 $\rightarrow$ Gln substitution in thrombin mimics the catalytic switch induced by thrombomodulin. Proc Natl Acad Sci USA 88:7371-7375.

Liu LW, Vu TKH, Esmon CT, Coughlin SR. 1991a. The region of the thrombin receptor resembling hirudin binds to thrombin and alters enzyme specificity. J Biol Chem 266:16977-16980.

Liu LW, Ye J, Johnson AE, Esmon CT. 1991b. Proteolytic formation of either of the two prothrombin activation intermediates results in formation of a hirugen binding site. $J$ Biol Chem 266:23632-23636.

Luzatti V. 1952. Traitement statistique des erreurs dans la determination des structures cristallines. Acta Crystallogr 5:802-810.

Madison EI, Kobe A, Gething MJ, Sambrook JF, Goldsmith EJ. 1993. Converting tissue plasminogen activator to a zymogen: A regulatory triad of Asp-His-Ser. Science 262:419-421.

Mann KG. 1976. Prothrombin. In: Lorand L, ed. Methods in enzymology, proteolytic enzymes, $X L V$, part $B$. New York: Academic Press. pp 123156.

Mann KG. 1987. The assembly of blood clotting complexes on membranes. Trends Biochem Sci 12:229-233.

Mao SJT, Yates MT, Owen TJ, Krstenansky JL. 1988. Interaction of hirudin with thrombin: Identification of a minimal binding domain of hirudin that inhibits clotting activity. Biochemistry 27:8170-8173.

Maryanoff BE, Qiu X, Padmanabhan KP, Tulinsky A, Almond HR, Andrade-Gordon P, Greco MN, Kauffman JA, Nicolaou KG, Liu A, Brungs PH, Fusetani N. 1993. Molecular basis for the inhibition of human $\alpha$-thrombin by the macrocyclic peptide cyclotheonamideA. Proc Natl Acad Sci USA 90:8048-8052.

Mathews II, Padmanabhan KP, Ganesh V, Tulinsky A, Ishii M, Chen J, Turck CW, Coughlin SR, Fenton JW II. 1994. Crystallographic structures of thrombin complexed with thrombin receptor peptides: Existence of expected and novel binding modes. Biochemistry 33:3266-3279.

Mathews II, Tulinsky A. 1995. Active site mimetic inhibition of thrombin. Acta Crysiallogr D. Forthcoming.

Naski MC, Fenton JW II, Maraganore JM, Olson ST, Shafer JA. 1990. The $\mathrm{COOH}$-terminal domain of hirudin: An exosite-directed competitive in hibitor on the action of $\alpha$-thrombin on fibrinogen. $J$ Biol Chem 265 : 13484-13489.

Ni F, Ning Z, Jackson CM, Fenton JW II. 1993. Thrombin exosite for fibrinogen recognition is partially accessible in prothrombin. $J$ Biol Chem 268:16899-16902.

Ni F, Ripoll DR, Martin PD, Edwards BFP. 1992. Solution structure of a platelet receptor peptide bound to bovine $\alpha$-thrombin. Biochemistry 31 : 11551-11557.

Padmanabhan K, Padmanabhan KP, Tulinsky A, Park CH, Bode W, Huber R, Blankenship DT, Cardin AD, Kisiel W. 1993. Structure of human des (1-45)-Factor Xa at $2.2 \AA \AA$ resolution. J Mol Biol 232:947-966.

Parry MAA, Stone SR, Hofsteenge J, Jackman MP. 1993. Evidence for common structural changes in thrombin induced by active-site or exosite binding. Biochem $J$ 290:665-670.

Priestle JP. 1988. RIBBON: A stereo cartoon drawing program for proteins. $J$ Appl Crystallogr 21:572-576.

Priestle JP, Rahuel J, Rink H, Tones M, Grutter MG. 1993. Changes in interaction in complexes of hirudin derivatives and human $\alpha$-thrombin due to different crystal forms. Protein Sci 2:1630-1642.

Qiu X, Padmanabhan KP, Carperos VE, Tulinsky A, Kline T, Maraganore JM, Fenton JW II. 1992. Structure of the hirulog 3-thrombin complex and nature of the $\mathrm{S}^{\prime}$ subsites of substrates and inhibitors. Biochemistry $31: 11689-11697$

Qiu X, Yin M, Padmanabhan KP, Krstenansky JL, Tulinsky A. 1993. Structures of thrombin complexes with a designed and natural exosite peptide inhibitor. $J$ Biol Chem 268:20318-20326.

Robertus JD, Kraut J, Alden RA, Birktoft JJ. 1972. Subtilisin: A stereochemical mechanism involving transition-state stabilization. Biochemistry $11: 4293-4303$.

Rydel TJ, Ravichandran KG, Tulinsky A, Bode W, Huber R, Roitsch C, Fenton JW II. 1990. The structure of a complex of recombinant hirudin and human $\alpha$-thrombin. Science 249:277-280.

Rydel TJ, Tulinsky A, Bode W, Huber R. 1991. Refined structure of the hirudin-thrombin complex. J Mol Biol 221:583-601.

Rydel TJ, Yin M, Padmanabhan KP, Blankenship DT, Cardin AD, Correa PM, Fenton JW II, Tulinsky A. 1994. Crystallographic structure of human $\gamma$-thrombin. J Biol Chem 269:22000-22006. 
Schechter I, Berger A. 1967. On the size of the active site in proteases. I. Papain. Biochem Biophys Res Commun 27:157-162.

Singh TP, Bode W, Huber R. 1980. Low temperature protein crystallography. Effect on flexibility, temperature factor, mosaic spread, extinction and diffuse scattering in two examples: Bovine trypsinogen and $\mathrm{Fc}$ fragment. Acta Crystallogr B 36:621-627.

Skrzypczak-Jankun E, Carperos VE, Ravichandran KG, Tulinsky A, Westbrook M, Maraganore JM. 1991. Structure of the hirugen and hirulog 1 complexes of $\alpha$-thrombin. $J$ Mol Biol 221:1379-1393.

Skrzypczak-Jankun E, Rydel TJ, Tulinsky A, Fenton JW II, Mann KG. 1989. Human D-phe-pro-arg- $\mathrm{CH}_{2}-\alpha$-thrombin crystallization and diffraction data. J Mol Biol 206:755-757.

Stevens WK, Nesheim ME. 1993. Structural changes in the protease domain of prothrombin upon activation as assessed by $N$-bromosuccinimide modification of tryptophan residues in prethrombin- 2 and thrombin. Biochemistry 32:2787-2794.

Thaller C, Eichele G, Weaver LH, Wilson E, Karlsson R, Jansonius JN. 1985. Seed enlargement and repeated seeding. Methods Enzymol 114:132-135.
Venkatachalam CM. 1968. Stereochemical criteria for polypeptides and proteins. I. Conformation of a system of three linked peptide units. Biopolymers $6: 1425-1436$.

Walter J, Steigemann W, Singh TP. 1982. On the disordered activation domain in trypsinogen: Chemical labelling and low temperature crystallography. Acta Crystallogr B 38:1462-1472.

Wang D, Bode W, Huber R. 1985. Bovine chymotrypsinogen A: X-ray crystal structure analysis and refinement of a new crystal form at $1.8 \AA$ resolution. J Mol Biol 185:595-624.

Wright HT. 1973. Activation of chymotrypsinogen-A: A hypothesis based upon comparison of the crystal structures of chymotrypsinogen-A and $\alpha$-chymotrypsin. J Mol Biol 79:13-23.

Wu Q, Picard V, Aiach M, Sadler JE. 1994. Activator-induced exposure of the thrombin anion-binding exosite. J Biol Chem 269:3725-3730.

Zdanov A, Wu S, DiMaio J, Konishi Y, Li Y, Wu X, Edwards BFP, Martin PD, Cygler M. 1993. Crystal structure of the complex of human $\alpha$ thrombin and nonhydrolyzable bifunctional inhibitors, hirutonin-2 and hirutonin-6. Proteins Struct Funct Genet 17:252-265. 